\title{
Mechanistic origin of the diverging selectivity patterns in catalyzed ethane and ethene oxychlorination
}

\author{
Matthias Scharfe ${ }^{\mathrm{a}}$, Guido Zichittella ${ }^{\mathrm{a}}$, Vita A. Kondratenko ${ }^{\mathrm{b}}$, Evgenii V. Kondratenko ${ }^{\mathrm{b}}$, Núria López ${ }^{\mathrm{c}, *}$, \\ Javier Pérez-Ramírez ${ }^{\mathrm{a}, *}$ \\ ${ }^{a}$ Institute for Chemical and Bioengineering, Department of Chemistry and Applied Biosciences, ETH Zurich, Vladimir-Prelog-Weg 1, 8093 Zurich, Switzerland \\ ${ }^{\mathrm{b}}$ Leibniz-Institut für Katalyse e.V., Albert-Einstein-Straße 29a, 18059 Rostock, Germany \\ ${ }^{\mathrm{c}}$ Institute of Chemical Research of Catalonia (ICIQ), The Barcelona Institute of Science and Technology, Av. Països Catalans 16, 43007 Tarragona, Spain
}

\begin{abstract}
A B S T R A C T
In the context of vinyl chloride monomer (VCM) production, an oxychlorination catalyst that allows direct VCM formation from gas-derived ethane instead of expensive oil-derived ethene is intensively sought after. A wide range of stable ethane oxychlorination catalysts for this purpose have recently been reported, yet they mainly yield ethene, while VCM remains a minor by-product. Strikingly, the same catalysts are active in ethene oxychlorination, resulting in selective VCM formation under equivalent reaction conditions. This work reveals the origin of these diverging selectivity patterns by combining quantitative catalytic tests, temporal analysis of products (TAP), and density functional theory (DFT) on iron phosphate. Ethane oxychlorination is found to proceed sequentially through ethyl chloride (EtCl) dehydrochlorination to ethene, while ethene oxychlorination directly yields VCM without formation of the intermediate dichloroethane (EDC) on iron phosphate. Furthermore, by co-feeding ethane in ethene oxychlorination, we demonstrate that the alkane suppresses the formation of VCM in ethene oxychlorination. The reason for this VCM inhibition is found in the hydrocarbon competition for a combination of the active, free and chlorinated iron centers. As ethane activation exhibits half of the barrier of ethene activation, the presence of ethane leads to active site depletion, hindering VCM formation. These observations are extended by ethane co-feeding tests in ethene oxychlorination over a wide range of known oxychlorination catalysts $\left(\mathrm{EuOCl}, \mathrm{LaOCl}, \mathrm{CeO}_{2}\right.$, and $\left.\mathrm{CuCl}_{2}-\mathrm{KCl}-\mathrm{LaCl}_{3} / \gamma-\mathrm{Al}_{2} \mathrm{O}_{3}\right)$, and corresponding DFT calculations, indicating that the described phenomenon is material independent. The gathered molecular-level understanding explains the major hurdle of using ethane as feedstock for vinyl chloride production.
\end{abstract}

\section{Introduction}

Polyvinyl chloride (PVC) is the third most produced synthetic polymer today with a market size of $>53$ billion USD, which is growing at an annual rate of $5.3 \%$ [1]. Whilst the corresponding vinyl chloride monomer (VCM, $\mathrm{C}_{2} \mathrm{H}_{3} \mathrm{Cl}$ ) was originally produced through hydrochlorination of coal-derived acetylene over $\mathrm{HgCl}_{2}$ catalysts, expansion of the demand in the 1950s prompted a feedstock shift to cheaper oil-derived ethene in most countries except for China due to large coal reserves [2-4]. This alternative route comprises chlorination of ethene, which is performed over $\mathrm{FeCl}_{3}$ catalysts and yields the intermediate product ethylene dichloride (EDC, $\mathrm{C}_{2} \mathrm{H}_{4} \mathrm{Cl}_{2}$ ), which is thermally dehydrochlorinated in a second

\footnotetext{
* Corresponding authors.

E-mail addresses: nlopez@iciq.es (N. López),jpr@chem.ethz.ch (J. Pérez-Ramírez).
}

step to VCM [2,3]. The hydrogen chloride $(\mathrm{HCl})$ released as a stoichiometric byproduct of the overall process is recycled by ethene oxychlorination to EDC over promoted alumina-supported $\mathrm{CuCl}_{2}$ catalysts [2,3,5-17]. Nevertheless, the instability of the copper chloride system, resulting in its volatilization due to hot spot formation or particle stickiness in fixed-bed or fluidized-bed reactors, constitutes a persisting challenge [18]. In view of the growing PVC demand and dwindling oil reserves, three major breakthroughs in VCM production are intensively sought after: $(i)$ the development of more robust ethene oxychlorination catalysts, (ii) process intensification via elimination of energy intensive EDC cracking, and (iii) feedstock change to the more abundant natural gas-derived ethane.

Recently, progress in items ( $i$ ) and (ii) was achieved by uncovering stable catalysts, such as $\mathrm{CeO}_{2}$ and $\mathrm{EuOCl}$, which offer the potential to obtain VCM from ethene in a single step $[19,20]$. In the 
search for a catalyst for VCM production through ethane oxychlorination for the milestone (iii), many $\mathrm{CuCl}_{2}$-based and copper-free systems, e.g. $\mathrm{K}_{4} \mathrm{Ru}_{2} \mathrm{OCl}_{10} / \mathrm{TiO}_{2}$ [21], $\mathrm{Fe}\left(\mathrm{P}_{2} \mathrm{O}_{7}\right)_{\times} / \mathrm{SiO}_{2}$ [22], or $\mathrm{FeCl}_{3}$ [23], were investigated, leading to mixtures of ethene, ethyl chloride, and VCM as the main products [24]. Copper-based catalysts typically exhibit a higher VCM selectivity than copper-free systems, which instead favor ethyl chloride and ethene formation $[7,14,21,24-30]$. Noteworthy exceptions to this rule are $\mathrm{LaOCl}$ or $\mathrm{FeCl}_{3}$, showing a VCM selectivity up to $79 \%[14,23]$. In addition, copper-based catalysts can reach productivities around $5.12 \mathrm{~g}_{\mathrm{VCM}}$ $\mathrm{g}_{\text {cat }}^{-1} \mathrm{~h}^{-1}$ [31], while copper-free catalysts generally suffer from very low productivity, in technical form around $0.05 \mathrm{~g}_{\mathrm{vcm}} \mathrm{g}_{\text {cat }}^{-1} \mathrm{~h}^{-1}$ $[14,21,23,27-30]$. On the other hand, the instability of copperbased systems at the higher required temperatures for ethane oxychlorination in comparison to ethene oxychlorination ( $c a .713 \mathrm{~K} v s$. $493 \mathrm{~K}$ ), poses a major drawback. Recently, a wide range of catalytic materials, including EuOCl, $\mathrm{FePO}_{4}, \mathrm{TiO}_{2},(\mathrm{VO})_{2} \mathrm{P}_{2} \mathrm{O}_{7}, \mathrm{CeO}_{2}$ [32], or TiC-SiC [33] demonstrated remarkable performance in ethane oxychlorination, exhibiting strikingly high selectivity to ethene with only minor ethyl chloride ( $\mathrm{EtCl}, \mathrm{C}_{2} \mathrm{H}_{5} \mathrm{Cl}$ ) formation, while reaching a productivity of $1 \mathrm{~g}_{\text {ethene }} \mathrm{g}_{\mathrm{cat}}^{-1} \mathrm{~h}^{-1}$ [32]. The formation of VCM was minimal ( $<5 \%$ for $\mathrm{EuOCl}$ and $\mathrm{FePO}_{4}$ at $20 \%$ conversion) over all materials, which contrasts the fact that some of these catalysts are excellent catalysts for ethene to VCM conversion [20]. Therefore, the virtual absence of VCM production during ethane oxychlorination on these copper-free catalysts, contrasting their high VCM selectivity in ethene oxychlorination as illustrated in Scheme 1, poses a riddle yet unsolved.

This study reveals that $\mathrm{FePO}_{4}$ exhibits the described diverging selectivity patterns in ethane and ethene oxychlorination and examines the underlying mechanistic reasons. To this end, steady-state kinetic tests, co-feeding experiments of ethane and ethyl chloride in ethene oxychlorination, temporal analysis of products (TAP), and density functional theory (DFT) calculations are performed in order to assess the magnitude of the diverging selectivity, the detrimental effect of ethane or ethyl chloride

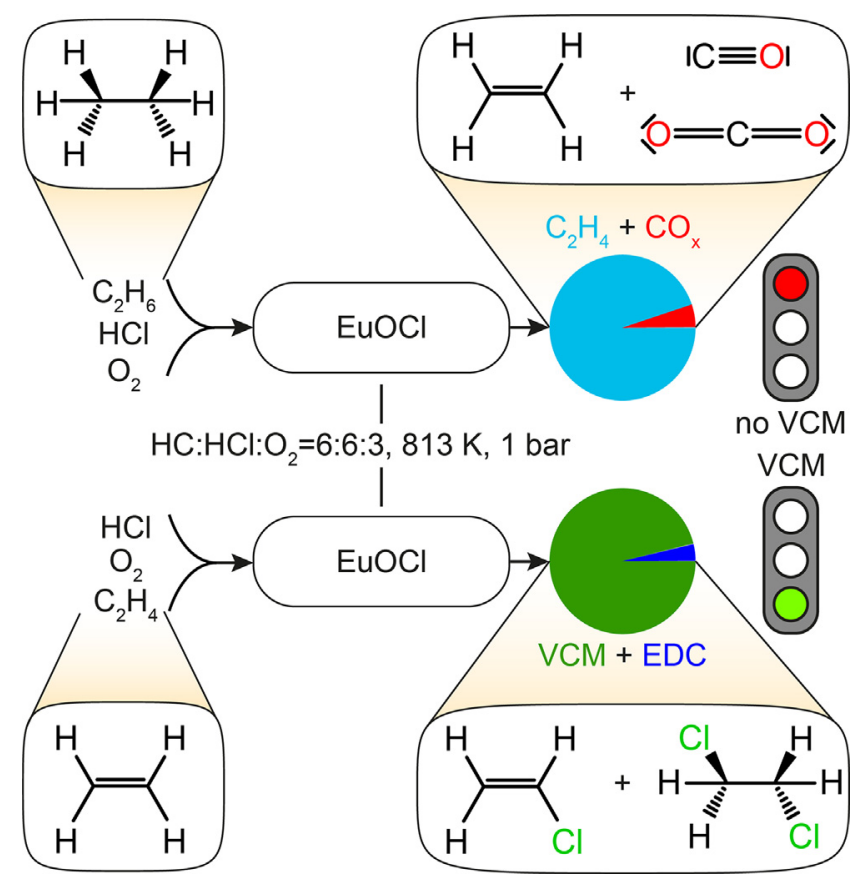

Scheme 1. Illustration depicting the typical differences in product distribution in oxychlorination processes depending on the hydrocarbon (HC) source over the same catalyst and under equivalent reaction conditions. The insets show the structural formulae of the hydrocarbon sources and products. presence on the VCM formation, and to reveal the mechanisms of ethane and ethene oxychlorination, responsible for the observed selectivity differences. The found reasoning applies also for other non-copper catalysts with similar selectivity patterns but very different structure ( $\mathrm{EuOCl}, \mathrm{LaOCl}, \mathrm{CeO}_{2}$ ), as evidenced by co-feeding studies and key DFT descriptors, hampering the potential of ethane as feedstock for PVC production.

\section{Experimental and computational methods}

\subsection{Catalyst preparation and characterization}

$\mathrm{FePO}_{4}$ and $\mathrm{CeO}_{2}$ were prepared according to procedures described in the literature [32,34]. EuOCl and $\mathrm{LaOCl}$ were prepared by exposure of the corresponding oxides, obtained by precipitation following a protocol reported elsewhere [20], to the standard oxychlorination conditions (Table 1 ) at $723 \mathrm{~K}$ for $6 \mathrm{~h}$. $\mathrm{CuCl}_{2}-\mathrm{KCl}-$ $\mathrm{LaCl}_{3} / \mathrm{Al}_{2} \mathrm{O}_{3}$ (hereafter abbreviated as $\mathrm{CuCl}_{2}$ for simplicity) was prepared by sequential incipient-wetness impregnation as previously described [19,35]. All catalysts were characterized by powder $\mathrm{X}$-ray diffraction (XRD) and $\mathrm{N}_{2}$ sorption in their as-prepared form and after ethane and ethene oxychlorination. XRD was measured using a PANalytical X'Pert PRO MPD diffractometer and $\mathrm{Cu}-\mathrm{K} \alpha$ radiation $(\lambda=0.15418 \mathrm{~nm})$. The data was recorded in the $10-70^{\circ} 2 \theta$ range with an angular step size of $0.017^{\circ}$ and a continuing time of 0.26 s per step. $\mathrm{N}_{2}$ sorption at $77 \mathrm{~K}$ was measured in a Micromeritics TriStar analyzer. Prior to the measurements, the samples were outgassed to $50 \mathrm{mbar}$ at $573 \mathrm{~K}$ for $12 \mathrm{~h}$. The Brunauer-Emmett-Teller (BET) method was applied to calculate the total surface area, $\mathrm{S}_{\mathrm{BET}}$, in $\mathrm{m}^{2} \mathrm{~g}^{-1}$.

\subsection{Catalytic evaluation}

Steady-state oxychlorination of ethene was investigated at ambient pressure in a continuous-flow fixed-bed reactor (Scheme S1). The set-up consists of (i) digital mass flow controllers (Bronkhorst ${ }^{\circledR}$ ) to dose $\mathrm{C}_{2} \mathrm{H}_{4}$ (PanGas, 3.5), $\mathrm{C}_{2} \mathrm{H}_{6}$ (PanGas, 3.5), $\mathrm{HCl}$ (Air Liquide, 2.8, anhydrous), $\mathrm{O}_{2}$ (Messer, $19.96 \%$ in $\mathrm{He}$ ), $\mathrm{EtCl}$ (PanGas, 5 vol.\% in He 5.0), He (PanGas, 5.0) as a carrier gas, and $\operatorname{Ar}$ (PanGas, 5.0) as an internal standard at a total volumetric flow, $F_{\mathrm{T}}$, of $100 \mathrm{~cm}^{3} \mathrm{STP} \mathrm{min}^{-1}$, (ii) a syringe pump (Nexus 6000, Chemyx) to feed EDC (Fluka, 99.5\%), (iii) a vaporizer operated at $403 \mathrm{~K}$, accommodating a quartz T-connector filled with glass beads to vaporize EDC, $(i v)$ an electrically heated oven hosting a quartz micro-reactor equipped with a K-type thermocouple whose tip reaches the center of the catalyst bed, $(v)$ downstream heat tracing to avoid any condensation of the reactants and products, and ( $v i)$ a gas chromatograph coupled to a mass spectrometer (GC-MS) for on-line analysis. The effluent stream was neutralized by passing it through an impinging bottle containing an aqueous $\mathrm{NaOH}$ solution $(1 \mathrm{M})$. The catalyst $\left(W_{\text {cat }}=0.5 \mathrm{~g}\right.$, particle size $\left.d_{\mathrm{p}}=0.4-0.6 \mathrm{~mm}\right)$ was loaded in the micro-reactor (10 $\mathrm{mm}$ inner diameter) and pretreated in He at $473 \mathrm{~K}$ for $30 \mathrm{~min}$. Prior to the analysis of the reaction mixtures, the catalysts were equilibrated for at least $1 \mathrm{~h}$ under each condition. Carbon-containing compounds in the effluent gas stream at the reactor outlet $\left(\mathrm{C}_{2} \mathrm{H}_{6}, \mathrm{C}_{2} \mathrm{H}_{4}\right.$, EtCl, EDC, VCM, $\mathrm{C}_{2} \mathrm{H}_{2} \mathrm{Cl}_{2}$ (DCE), $\mathrm{CH}_{4}, \mathrm{CH}_{3} \mathrm{Cl}, \mathrm{CO}$, and $\mathrm{CO}_{2}$ ) and $\mathrm{Ar}$ were quantified using an on-line gas chromatograph, equipped with a GS-Carbon PLOT column, which was coupled to a mass spectrometer (Agilent GC 7890B, Agilent MSD 5977A) with a triple-axis detector and an electron multiplier. The conversion of reactant $i, X_{i},\left(i: \mathrm{C}_{2} \mathrm{H}_{6}, \mathrm{C}_{2} \mathrm{H}_{4}\right.$, $\mathrm{C}_{2} \mathrm{H}_{5} \mathrm{Cl}$, or $\mathrm{C}_{2} \mathrm{H}_{4} \mathrm{Cl}_{2}$ ) was calculated using Eq. (1),

$X_{i}=\frac{n_{i}^{\text {inlet }}-n_{i}^{\text {outlet }}}{n_{i}^{\text {inlet }}} \times 100, \%$ 
Table 1

Reactions and conditions studied in this work. ${ }^{\mathrm{a}}$

\begin{tabular}{|c|c|c|c|c|c|c|c|c|c|}
\hline \multirow[t]{2}{*}{ Reaction } & \multirow[t]{2}{*}{$T / \mathrm{K}$} & \multicolumn{8}{|c|}{ Concentration/vol.\% } \\
\hline & & $\mathrm{C}_{2} \mathrm{H}_{6}$ & $\mathrm{C}_{2} \mathrm{H}_{4}$ & $\mathrm{EtCl}$ & EDC & $\mathrm{HCl}^{\mathrm{b}}$ & $\mathrm{O}_{2}$ & $\mathrm{Ar}^{\mathrm{C}}$ & $\mathrm{He}^{\mathrm{d}}$ \\
\hline \multicolumn{10}{|c|}{ Oxychlorination } \\
\hline \multicolumn{10}{|c|}{$-\mathrm{C}_{2} \mathrm{H}_{6}$} \\
\hline$-\mathrm{FePO}_{4}$ & $723-850$ & 6 & - & - & - & $1-15$ & 3 & 3 & $87-82$ \\
\hline - EuOCl & $673-850$ & 6 & - & - & - & $1-15$ & 3 & 3 & $87-82$ \\
\hline$-\mathrm{CeO}_{2}$ & $673-773$ & 6 & - & - & - & $1-15$ & 3 & 3 & $87-82$ \\
\hline - $\mathrm{LaOCl}$ & $723-873$ & 6 & - & - & - & $1-15$ & 3 & 3 & $87-82$ \\
\hline$-\mathrm{CuCl}_{2}$ & $523-623$ & 6 & - & - & - & $1-15$ & 3 & 3 & $87-82$ \\
\hline \multicolumn{10}{|l|}{$-\mathrm{C}_{2} \mathrm{H}_{4}$} \\
\hline$-\mathrm{FePO}_{4}$ & $673-850$ & - & 6 & - & - & $1-15$ & 3 & 3 & $87-82$ \\
\hline - EuOCl & $673-850$ & - & 6 & - & - & $1-15$ & 3 & 3 & $87-82$ \\
\hline$-\mathrm{CeO}_{2}$ & $573-850$ & - & 6 & - & - & $1-15$ & 3 & 3 & $87-82$ \\
\hline - LaOCl & $723-873$ & - & 6 & - & - & $1-15$ & 3 & 3 & $87-82$ \\
\hline$-\mathrm{CuCl}_{2}$ & $473-623$ & - & 6 & - & - & $1-15$ & 3 & 3 & $87-82$ \\
\hline \multicolumn{10}{|c|}{ Dehydrochlorination } \\
\hline$-\mathrm{C}_{2} \mathrm{H}_{5} \mathrm{Cl}$ & $545-673$ & - & 0 & 1 & - & 6 & 3 & 3 & 87 \\
\hline$-\mathrm{C}_{2} \mathrm{H}_{4} \mathrm{Cl}_{2}$ & $573-723$ & - & - & - & 1 & 6 & 3 & 3 & 87 \\
\hline \multicolumn{10}{|c|}{ Co-feeding in $\mathrm{C}_{2} \mathrm{H}_{4}$ oxychlorination and EDC dehydrochlorination } \\
\hline$-\mathrm{C}_{2} \mathrm{H}_{5} \mathrm{Cl}$ & 773 & - & 6 & $0-3$ & - & 6 & 3 & 3 & $82-79$ \\
\hline$-\mathrm{C}_{2} \mathrm{H}_{6}$ & 773 & $0-6$ & $6 / 0$ & - & $0 / 3$ & 6 & 3 & 3 & $82-76 / 85-79$ \\
\hline
\end{tabular}

a $F_{\mathrm{T}}=100 \mathrm{~cm}^{3} \mathrm{STP} \mathrm{min}^{-1}, W_{\text {cat }}=0.5 \mathrm{~g}, P=1 \mathrm{bar}$.

b Standard concentration: 6 vol.\%.

c Internal standard.

d Carrier gas.

where $n_{i}^{\text {inlet }}$ and $n_{i}^{\text {outlet }}$ are the molar flows of the reactant $i$ at the inlet and outlet of the reactor, respectively. Selectivity, $S_{j}$, and yield, $Y_{j}$, of product $j\left(j: \mathrm{C}_{2} \mathrm{H}_{6}, \mathrm{C}_{2} \mathrm{H}_{4}, \mathrm{EtCl}, \mathrm{EDC}, \mathrm{VCM}, \mathrm{DCE}, \mathrm{CH}_{4}, \mathrm{CH}_{3} \mathrm{Cl}, \mathrm{CO}\right.$, and $\mathrm{CO}_{2}$ ) were determined according to Eqs. (2) and (3),

$S_{j}=\frac{n_{j}^{\text {outlet }} \times N_{\mathrm{C}, j}}{\sum n_{j}^{\text {outlet }} \times N_{\mathrm{C}, j}} \times 100, \%$

$Y_{j}=\frac{X_{i} \times S_{j}}{100}, \%$

where $n_{j}$ outlet is the molar flow of the product $j$ at the reactor outlet. $N_{\mathrm{C} j}$ is the number of carbon atoms in the compound $j$. The error of the carbon balance, $\varepsilon_{\mathcal{C}}$, determined using Eq. (4),

$\varepsilon_{\mathrm{C}}=\frac{n_{i}^{\text {inlet }} \times N_{\mathrm{C}, i}-\left(n_{i}^{\text {outlet }} \times N_{\mathrm{C}, i}+\sum n_{j}^{\text {outlet }} \times N_{\mathrm{C}, j}\right)}{n_{i}^{\text {inlet }} \times N_{\mathrm{C}, i}} \times 100, \%$

where $N_{C, i}$ is the number carbon atoms in the compound $i$, of was less than $5 \%$ in all experiments, i.e., the carbon mass balance closed at $\geq 95 \%$. Calculation of the Weisz-Prater and Mears criteria together with catalytic tests in ethane oxychlorination with distinct particle size and different flow rates at constant residence time (Fig. S1) indicated that all catalytic tests were performed in the absence of heat and mass transport limitations. After the tests, the reactor was quenched to room temperature in He flow. Table S1 and Fig. S2 evidence that the structure and surface area of all investigated materials, except the reference $\mathrm{CuCl}_{2}$ catalyst, were stable during the oxychlorination tests.

\subsection{Temporal analysis of products}

Mechanistic aspects of $\mathrm{C}_{2} \mathrm{H}_{6}$ and $\mathrm{C}_{2} \mathrm{H}_{4}$ oxychlorination were studied by the temporal analysis of products using a TAP-2 reactor system, a transient pulse technique with a time resolution of approximately $100 \mu \mathrm{s}[36,37]$. The used TAP-2 system is equipped with an in-house developed quartz-tube fixed-bed reactor $\left(d_{\text {in }}=6 \mathrm{~mm}, L=40 \mathrm{~mm}\right)$. The pre-equilibrated catalyst $\left(W_{\text {cat }}=44\right.$ mg particle size $d_{\mathrm{p}}=0.3-0.5 \mathrm{~mm}$ ) was packed between two layers of quartz (particle size $d_{\mathrm{p}}=255-350 \mu \mathrm{m}$ ) within the isothermal zone of the reactor. Then, the reactor was evacuated stepwise to
$10^{-5} \mathrm{~Pa}$. The pulse experiments were carried out without any treatment at $773 \mathrm{~K}$ using $\mathrm{C}_{2} \mathrm{H}_{n}: \mathrm{Ne}=1: 1, \mathrm{C}_{2} \mathrm{H}_{n}: \mathrm{O}_{2}: \mathrm{Ne}=1: 1: 1$, and $\mathrm{HCl}$ : $\mathrm{Ar}=1: 1$ mixtures $(n=4,6)$. An overall pulse size was around $10^{16}$ molecules. $\mathrm{O}_{2}$ (Air Liquide, 4.8), $\mathrm{C}_{2} \mathrm{H}_{4}$ (Air Liquide, 3.5), $\mathrm{C}_{2} \mathrm{H}_{6}$ (Air Liquide, 2.5), $\mathrm{HCl}$ (Air Liquide, 4.5, anhydrous), Ne (Linde Gas, 5.0) and $\operatorname{Ar}$ (5.0, Linde Gas) were used for preparing reaction mixtures without additional purification. A quadrupole mass spectrometer (HAL RC 301 Hiden Analytical) was used for quantitative analysis of feed components and reaction products where the following AMUs were assigned for mass-spectrometric compound identification: $70\left(\mathrm{Cl}_{2}\right), 66(\mathrm{EtCl}), 64(\mathrm{EtCl}, \mathrm{EDC}, \mathrm{VCM})$, 62 (EDC, VCM), 49 (EDC), $44\left(\mathrm{CO}_{2}\right), 36(\mathrm{HCl}), 32\left(\mathrm{O}_{2}\right), 29\left(\mathrm{C}_{2} \mathrm{H}_{6}\right.$, $\mathrm{EtCl}), 28\left(\mathrm{EtCl}, \mathrm{EDC}, \mathrm{C}_{2} \mathrm{H}_{6}, \mathrm{C}_{2} \mathrm{H}_{4}, \mathrm{CO}_{2}, \mathrm{CO}\right), 27$ (EtCl, EDC, VCM, $\left.\mathrm{C}_{2} \mathrm{H}_{6}, \mathrm{C}_{2} \mathrm{H}_{4}\right), 26$ (EtCl, EDC, VCM, $\left.\mathrm{C}_{2} \mathrm{H}_{6}, \mathrm{C}_{2} \mathrm{H}_{4}\right), 22(\mathrm{Ne}), 18\left(\mathrm{H}_{2} \mathrm{O}\right), 2$ $\left(\mathrm{H}_{2} \mathrm{O}, \mathrm{H}_{2}\right), 40(\mathrm{Ar})$ and $20(\mathrm{Ar}, \mathrm{Ne})$. Pulses were repeated 10 times for each AMU and averaged to improve the signal-to-noise ratio.

\subsection{Computational details}

All calculations were performed with periodic boundary conditions at the density functional theory level, as implemented in the Vienna ab initio simulation package (VASP, version 5.3.5) [38-40], using the Perdew-Burke-Ernzerhof (PBE) functional [41]. In order to reduce the self-interaction error, an effective Hubbard potential ( $\left.U_{\text {eff }}\right)[42]$ was added to the Fe $3 d$ states. The parameter was optimized to match the measured band-gap of $E_{\text {gap }}=4.97 \mathrm{eV}$, leading to $E_{\text {gap }}=4.95 \mathrm{eV}$ at $U_{\text {eff }}=4.3 \mathrm{eV}$ using a $4 \times 4 \times 1 \quad \Gamma$-centered kpoint mesh and an energy cut-off of $700 \mathrm{eV}$, in accordance with the literature $U_{\text {eff }}$ values for monoclinic $\mathrm{FePO}_{4}$ [43-45]. Van der Waals contributions were included by using the D3 dispersion correction method of Grimme et al. [46]. Projector-augmented wave (PAW) pseudopotentials were used to consider the inner electrons, whereas valence electronic states were expanded in plane-waves with an energy cut-off of $500 \mathrm{eV}$ [47]. The criteria for electronic and geometry optimization convergence were set to $10^{-6} \mathrm{eV}$ and $0.015 \mathrm{eV} \AA^{-1}$, respectively. The lattice parameters of trigonal $\mathrm{FePO}_{4}$ (space group $\mathrm{P} 3{ }_{1} 21$ ) were optimized with the same k-point mesh and energy cut-off, leading to $a_{\text {calc }}=b_{\text {calc }}=5.070 \AA$ and $c_{\text {calc }}=11.345 \AA$, which are in good agreement with the experimental values of $a_{\exp }=b_{\exp }=5.044 \AA$ and $c_{\exp }=11.265 \AA$ [48]. All 
calculations were performed with spin polarization and since the antiferromagnetic (AF) solution was found to be energetically favored over the ferromagnetic solution, all results correspond to this AF solution. The investigated ( $\left.\begin{array}{lll}1 & 0 & 2\end{array}\right)$ surface was thereafter modeled as periodically repeated slabs using a $1 \times 1 \times 1 \quad \Gamma$ centered k-point mesh. The slabs were separated by $15 \AA$ of vacuum space on top and consisting of a $(3 \times 1)$ supercell with three layers of $\mathrm{Fe}$ atoms and $\mathrm{PO}_{4}$ groups, of which the upper two layers were allowed to relax. Undercoordinated oxygen atoms in phosphate groups at the top and bottom surface cuts were capped with hydrogen in order to balance the excess charge, resulting in a total of $12 \mathrm{H}$ atoms per slab, which were also allowed to relax. Gas-phase molecules were calculated in a periodically repeated cubic cell with a side length of $15 \AA$. The climbing image nudged elastic band (CI-NEB) method and corresponding vibrational analysis were used to locate and identify the transition states in the reaction network $[49,50]$. Calculations for $\mathrm{CeO}_{2}$, $\mathrm{EuOCl}$, and $\mathrm{LaOCl}$ were performed following our previous studies on ethene oxychlorination over $\mathrm{CeO}_{2}$ [34]. The structures, labeled as described in this work are freely accessible from the ioChem-BD database [51,52].

\section{Results and discussion}

\subsection{Iron phosphate in ethane and ethene oxychlorination}

Assessment of the performance of iron phosphate in ethane and ethene oxychlorination showed that both reactions proceed in a similar temperature region, leading to the same conversion of
$50 \%$ at the maximum investigated temperature (Fig. 1a). However at lower temperatures, the conversion-temperature relation changes in favor of ethene oxychlorination, which exhibits $20 \%$ conversion already at $50 \mathrm{~K}$ lower temperature than its ethane oxychlorination counterpart. Comparing the product distribution at this conversion level (Fig. 1b), reveals that ethane oxychlorination leads to $>90 \%$ ethene with the only by-product being ethyl chloride, while ethene oxychlorination yields VCM and combustion products $\left(\mathrm{CO}\right.$ and $\mathrm{CO}_{2}$ ). Considering the high selectivity towards ethene in ethane oxychlorination and the fact that ethyl chloride is known to be a reaction intermediate which is dehydrochlorinated on the catalyst surface, in turn closing the $\mathrm{HCl}$ loop and making $\mathrm{HCl}$ available for further reaction [53], the absence of any VCM is astonishing. Furthermore, even at various temperatures, the selectivity to ethene in ethane oxychlorination is only impaired by a higher fraction of ethyl chloride at low temperatures (Fig. S3), quickly reaching a plateau at elevated temperatures (Figs. 1c and S3). Just as little did a variation of the $\mathrm{HCl}$ feed content affect the selectivity to ethene, showing no VCM formation under any conditions (Figs. 1c and S3). Yet, higher $\mathrm{HCl}$ content led to increased conversion, exhibiting a reaction order with respect to $\mathrm{HCl}$ of $n_{\mathrm{HCl}}=0.45$. A complete removal of $\mathrm{HCl}$ or oxygen from the feed mixture at $813 \mathrm{~K}$, in order to estimate the degree of oxidative dehydrogenation of ethane or ethane chlorodehydrogenation, respectively, led to a drop of the conversion from $20 \%$ to $1 \%$ and below, rendering both contributions negligible. Investigating the equivalent conditions in ethene oxychlorination, the VCM selectivity exhibited a drop with increasing temperature to the benefit of
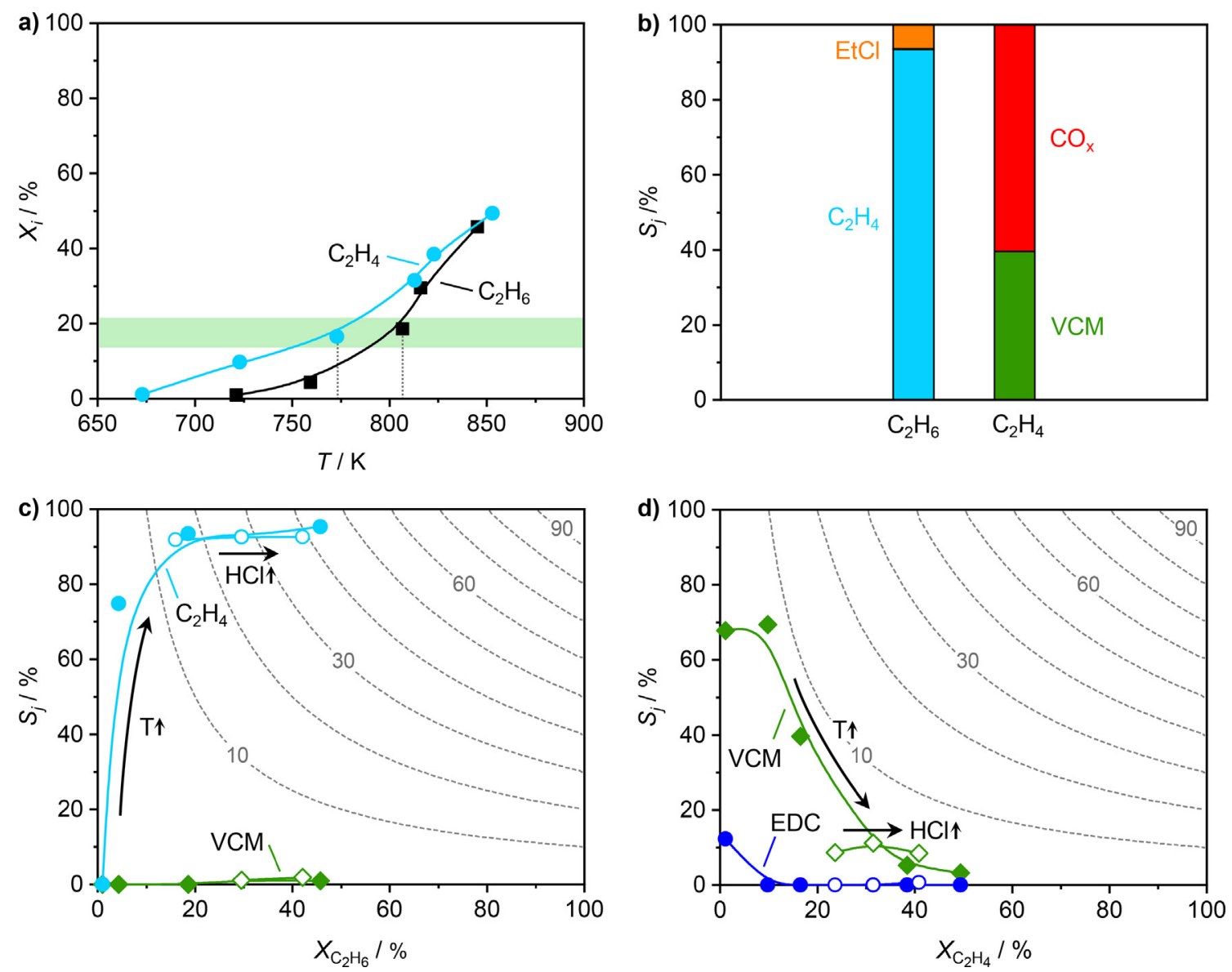

Fig. 1. (a) Conversion $\left(X_{i}\right)$ of ethane and ethene as a function of temperature in oxychlorination over FePO 4 . (b) Selectivity to products $\left(S_{j}\right)$ in ethane and ethene oxychlorination at $20 \%$ hydrocarbon conversion, as indicated by a green box in panel a). Selectivity to product $j$ as a function of (c) ethane and (d) ethene conversion in oxychlorination over $\mathrm{FePO}_{4}$, as derived from Figs. S3,4. The dotted gray lines denote the yield of product $j$, solid symbols indicate variable temperature corresponding to a), and open symbols variable $\mathrm{HCl}$ feed content $(1.5,6$, and 15 vol.\%). Conditions are detailed in Table 1 . 
CO or minor side-products, such as 1,2-dichloroethene (DCE), methane and methyl chloride. Strikingly, the usually observed reaction intermediate EDC $[19,20,34]$, was only observed as a trace compound at negligible conversion (i.e. at the lowest investigated temperature, Fig. 1d). Similar to ethane oxychlorination, the product distribution was not affected upon change of the $\mathrm{HCl}$ concentration, while the conversion was again boosted by increasing $\mathrm{HCl}$, which resulted in $n_{\mathrm{HCl}}=0.24$ (Figs. $1 \mathrm{~d}$ and S4).

In order to investigate the origin of VCM in ethene oxychlorination and the reason for its absence in ethane oxychlorination, the first step was to split the global oxychlorination reactions and consider their presumed partial constituents, the dehydrochlorination of the typical reaction intermediates ethyl chloride and EDC. Fig. 2a shows that the fully selective conversion of ethyl chloride to ethene is achieved at $75 \mathrm{~K}$ lower temperature with respect to starting ethane conversion in oxychlorination, which explains the low yield of ethyl chloride in the latter reaction (Fig. 1b). A similar shift of the conversion is observed in the selective EDC dehydrochlorination to VCM with respect to the global ethene oxychlorination (Fig. 2b). The observed temperature gap between the partial and global reaction is smaller for ethene oxychlorination than for ethane oxychlorination, which would suggest a higher fraction of $\mathrm{EDC}$ to VCM in ethene oxychlorination than of $\mathrm{EtCl}$ to ethene in ethane oxychlorination. However, as the opposite is observed in Figs. $1 \mathrm{~b}$ and $\mathrm{S} 3,4$, other mechanisms than fast consumption of
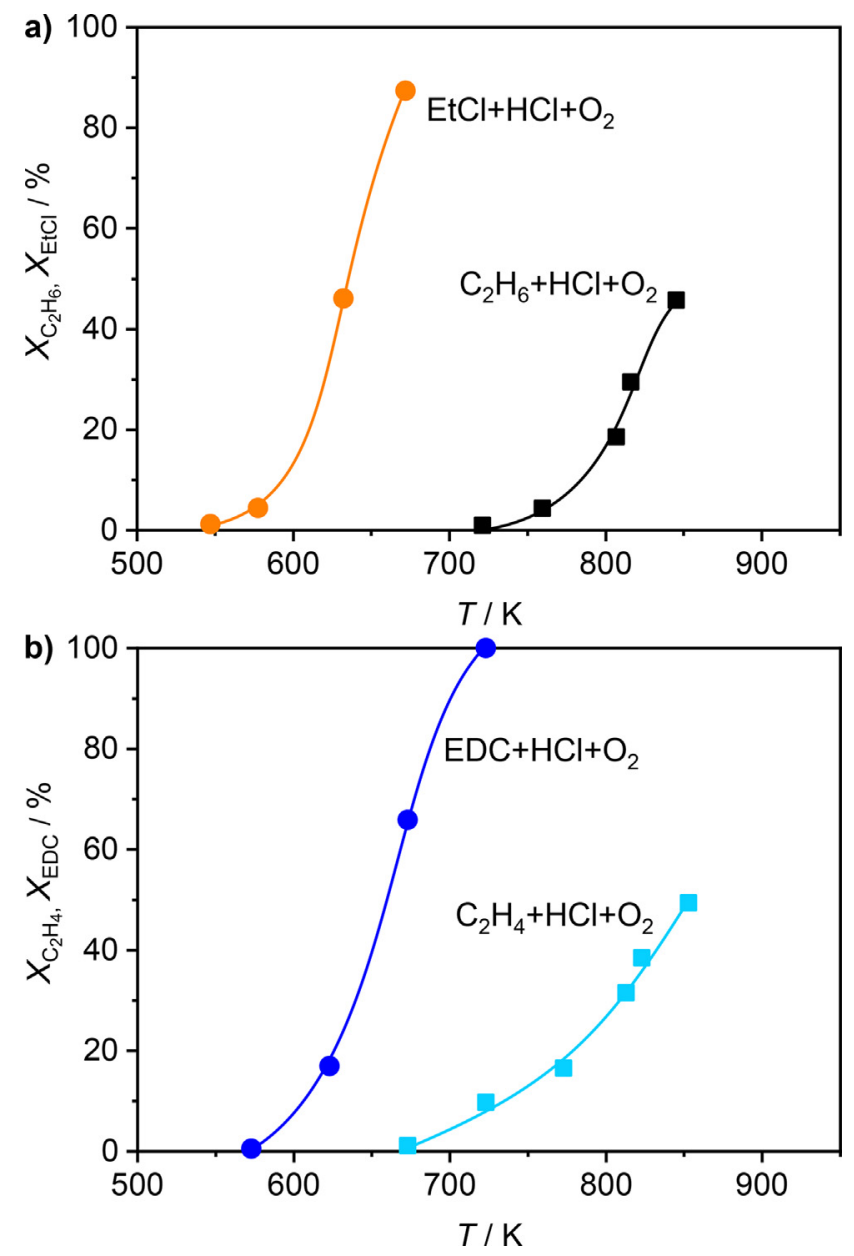

Fig. 2. (a) Conversion of ethane (black squares) and ethyl chloride (orange circles) in ethane oxychlorination and ethyl chloride dehydrochlorination as a function of temperature over $\mathrm{FePO}_{4}$. (b) Conversion of ethene (light blue squares) and EDC (blue circles) in ethene oxychlorination and EDC dehydrochlorination as a function of temperature over $\mathrm{FePO}_{4}$. Conditions are detailed in Table 1.
EDC must be responsible for its absence in ethene oxychlorination over $\mathrm{FePO}_{4}$. Based on previous literature [19,20,34,53,54], an overall sequential mechanism for ethane oxychlorination with the desired end-product VCM could be formulated as $\mathrm{C}_{2} \mathrm{H}_{6} \rightarrow$ $\mathrm{C}_{2} \mathrm{H}_{5} \mathrm{Cl} \rightarrow \mathrm{C}_{2} \mathrm{H}_{4} \rightarrow \mathrm{C}_{2} \mathrm{H}_{4} \mathrm{Cl}_{2} \rightarrow \mathrm{C}_{2} \mathrm{H}_{3} \mathrm{Cl}$, which is questionable due to the absence of VCM in ethane oxychlorination and EDC in ethene oxychlorination. In general, a useful technique to corroborate or discard such sequential mechanisms in addition to steady-state tests is the temporal analysis of products, performed by pulsing the reaction mixture over equilibrated catalysts in high vacuum, which reveals the order of appearance of products [37].

Fig. 3a shows the height-normalized transient response of ethane, ethyl chloride, ethene, and $\mathrm{HCl}$, recorded after simultaneous pulsing of $\mathrm{C}_{2} \mathrm{H}_{6}, \mathrm{O}_{2}$, and $\mathrm{HCl}$ (ethane oxychlorination) over pre-equilibrated $\mathrm{FePO}_{4}$. Most importantly, no traces of VCM could be observed thus corroborating the previously determined selectivity patterns under ambient pressure steady-state conditions. Even though the activity of the catalyst under high-vacuum conditions was low, due to low catalyst coverage and low contact times, ethyl chloride could be detected as the first product with the shortest delay compared to ethane, while the response of ethene is shifted to longer times. The appearance order of both carboncontaining products indicates that ethyl chloride is directly formed from ethane and then converted into ethene. Direct formation of ethene from ethane could be excluded as ethane dehydrogenation was found negligible, as also rationalized by DFT (vide infra). When $\mathrm{C}_{2} \mathrm{H}_{4}, \mathrm{O}_{2}$, and $\mathrm{HCl}$ were simultaneously pulsed (ethene oxychlorination), VCM was the only chlorine containing product (Fig. $3 \mathrm{~b}$ ), while EDC could not even be detected in trace amounts. This indicates that (i) EDC is not formed from ethylene or (ii) EDC is quickly converted into VCM. However, the latter is unlikely as under TAP conditions, even trace amounts can be detected due to easy desorption from the surface in high vacuum and very short contact times. Furthermore, EtCl (which is visible in Fig. 3a) dehydrochlorination proceeds in the same temperature region as EDC dehydrochlorination (Fig. 2), which would suggest similar ratios of $\mathrm{EDC} / \mathrm{VCM}$ and EtCl to ethene. Therefore, achieving a near to complete conversion of EDC under TAP conditions is improbable, which leads to the conclusion that VCM most likely originates directly from ethene. Thus, the expected cascade mechanism as observed on $\mathrm{CeO}_{2}$ [34], does not seem to be valid for $\mathrm{FePO}_{4}$. Interestingly, in addition to expected $\mathrm{EtCl}, \mathrm{VCM}$ could be observed as a product upon simultaneous pulsing of $\mathrm{C}_{2} \mathrm{H}_{6}$ and $\mathrm{HCl}$ (ethane chlorodehydrogenation, Fig. 3c), although no conversion was detected in steady-state ambient-pressure tests.

One possible explanation for the appearance of $\mathrm{EtCl}$ and particularly VCM under transient vacuum conditions can be formulated as follows. On one hand, the activity for ethane oxychlorination in the absence of oxygen at ambient pressure is low due to the absence of a hydrogen sink. On the other hand, the degree of surface chlorination of the pre-equilibrated $\mathrm{FePO}_{4}$ is high (at least in steady-state conditions). Such sites and lattice oxygen of $\mathrm{FePO}_{4}$ may still activate ethane through chlorination and hydrogen abstraction thus leading to $\mathrm{EtCl}$ and $\mathrm{C}_{2} \mathrm{H}_{4}$ respectively. These reactions also run at ambient pressure but quickly stop due to irreversible blockage of lattice oxygen sites under continuous flow operation. Owing to low amounts of pulsed compounds in the TAP tests compared to the steady-state experiments, it is possible to probe these sites for oxygen-free halogenation of ethane. The presence and reactivity of chlorinated iron sites on the surface of pre-equilibrated $\mathrm{FePO}_{4}$ was proven by single pulsing of $\mathrm{C}_{2} \mathrm{H}_{4}$, which led to VCM as the only detected product (Fig. 3d). Therefore, we can exclude any gas-phase reactions leading to VCM but conclude that the latter is formed through a reaction of $\mathrm{C}_{2} \mathrm{H}_{4}$ with adsorbed $\mathrm{Cl}$ through a $\mathrm{C}_{2} \mathrm{H}_{4} \mathrm{Cl}$ intermediate as suggested by DFT calculations (see Section 3.3). In conclusion, ethane and ethene 

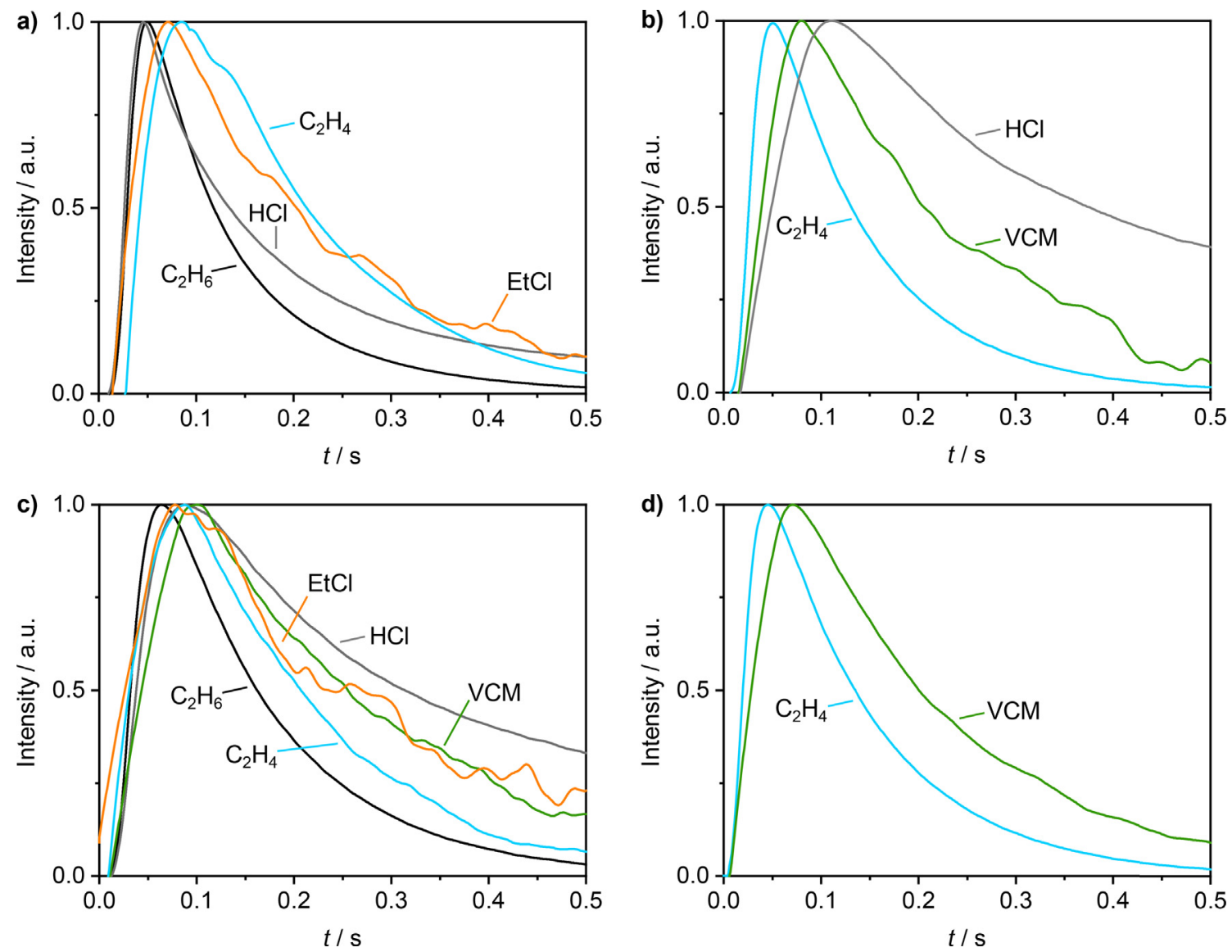

Fig. 3. Normalized transient responses of (a) $\mathrm{C}_{2} \mathrm{H}_{6}$, EtCl, $\mathrm{C}_{2} \mathrm{H}_{4}$, and $\mathrm{HCl}$ upon simultaneous pulsing of $\mathrm{HCl}: \mathrm{Ar}=1: 1$ and $\mathrm{C}_{2} \mathrm{H}_{6}: \mathrm{O}_{2}: \mathrm{Ne}=1: 1: 1$ at $773 \mathrm{~K},(\mathrm{~b}) \mathrm{C}_{2} \mathrm{H}_{4}, \mathrm{VCM}$, and $\mathrm{HCl}$ upon simultaneous pulsing of $\mathrm{HCl}: \mathrm{Ar}=1: 1$ and $\mathrm{C}_{2} \mathrm{H}_{4}: \mathrm{O}_{2}: \mathrm{Ne}=1: 1: 1$ at $773 \mathrm{~K},(\mathrm{c}) \mathrm{C}_{2} \mathrm{H}_{6}, \mathrm{EtCl}, \mathrm{C}_{2} \mathrm{H}_{4}, \mathrm{VCM}$, and $\mathrm{HCl}$ upon simultaneous pulsing of $\mathrm{HCl}: \mathrm{Ar}=1: 1$ and $\mathrm{C}_{2} \mathrm{H}_{6}: \mathrm{Ne}=1: 1: 1$ at $773 \mathrm{~K}$, and (d) $\mathrm{C}_{2} \mathrm{H}_{4}$, and VCM upon single pulsing of $\mathrm{C}_{2} \mathrm{H}_{4}: \mathrm{Ne}=1: 1$ at $773 \mathrm{~K}$. The raw data corresponding to the here depicted low-pass filtered data, is provided in Fig. $\mathrm{S} 5$.

seem to compete for activation on the surface, which is shifted to the favor of ethene to VCM transformation when oxygen is removed from the reaction. This demonstrates that indeed, ethane to VCM transformation is possible under certain conditions following a sequential pathway, however due to low catalyst activity, this situation is irrelevant under practical conditions. Still, the question remains how this mechanism is altered under standard reaction conditions, which leads to a suppression of VCM formation in ethane oxychlorination.

\subsection{Ethane as VCM suppression agent}

In order to assess if any species in ethane oxychlorination hamper further transformation of ethene to VCM, ethyl chloride or ethane were co-fed in ethene oxychlorination and EDC dehydrochlorination, as schematized in Fig. 4a. Briefly, ethene oxychlorination was performed at fixed conditions with $20 \%$ conversion (as highlighted in green in Fig. 1a) at $773 \mathrm{~K}$, prior to adding ethyl chloride or ethane to the feed mixture at the expense of the carrier gas, keeping the same total flow rate and $\mathrm{C}_{2} \mathrm{H}_{4}, \mathrm{HCl}$, and $\mathrm{O}_{2}$ concentrations. At the same time, the partial ethene and VCM pressures were monitored in the reactor effluent stream. EDC dehydrochlorination was performed at the same temperature and equivalent feed ratios. Fig. 4b shows that the partial ethene pressure increased significantly upon addition of ethyl chloride to the feed, which can be explained with the easy dehydrochlorination of ethyl chloride to ethene (Fig. 2a), while the concurrent slight increase of the partial VCM pressure is related to more available ethene, being transformed to vinyl chloride with a $c a .10 \%$ yield under these conditions (Fig. 2d). This evidences that ethyl chloride does not negatively affect the formation of VCM in ethene oxychlorination and is thus not responsible for its absence in ethane oxychlorination. Co-feeding of ethane also shows an increase of the partial ethene pressure with rising ethane pressure, due to proceeding ethane to ethene transformation (Fig. 4c). However, in contrast to the situation with ethyl chloride co-feeding, the partial VCM pressure decreases upon increase of the ethane pressure. Even though more ethene becomes available for oxychlorination with higher partial ethane pressures, VCM formation drops to lower levels than its starting point and is increasingly hindered with more ethane present in the feed. This indicates that ethane has a poisoning effect on the transformation of ethene to VCM. Even though TAP suggests that VCM is mainly directly formed from ethene in ethene oxychlorination, and EDC was not observed in the steady-state tests, small amounts of EDC were observed during ethyl chloride and ethane co-feeding in ethene oxychlorination (Fig. S6). The partial pressures essentially follow the trends for VCM, yet with a slightly reduced slope, indicating that EDC formation is promoted by ethyl chloride and first enabled, yet then suppressed by ethane. Interestingly, in EDC dehydrochlorination, ethane also hinders VCM formation (Fig. 4d), again evidencing interference of ethane in the mechanism. Therefore, ethane itself is established as a VCM suppression agent in ethane oxychlorination, still the exact root cause is unknown, which is investigated by theoretical considerations.

\subsection{Active site competition as selectivity descriptor}

In a first step, DFT calculations revealed the adsorption energies of reactants and products of ethane and ethene oxychlorination on 
a)

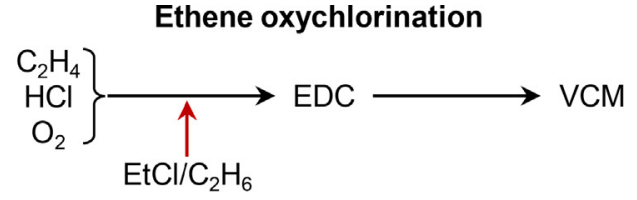

EDC dehydrochlorination
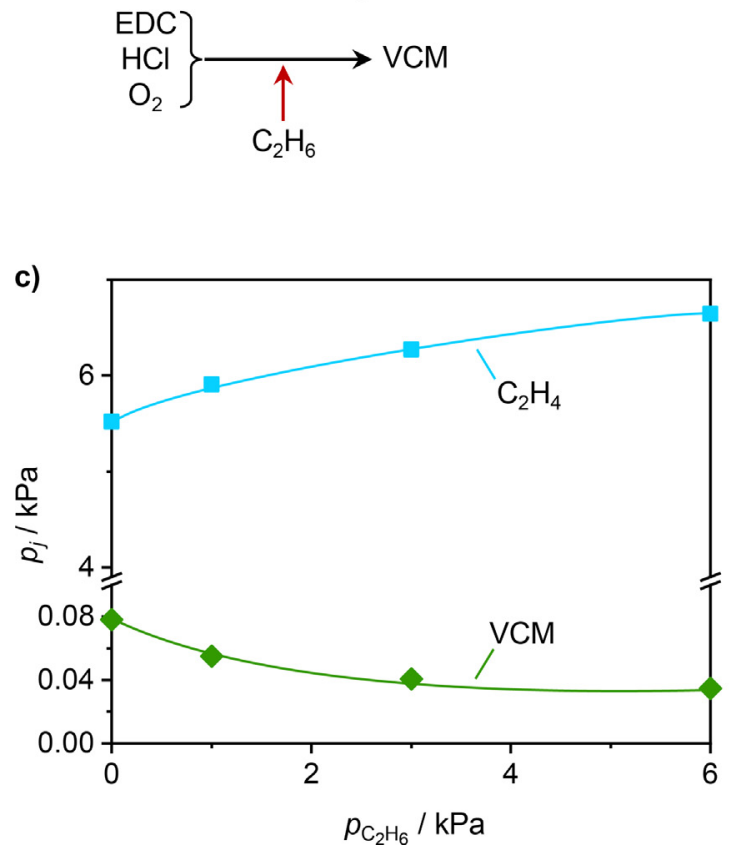
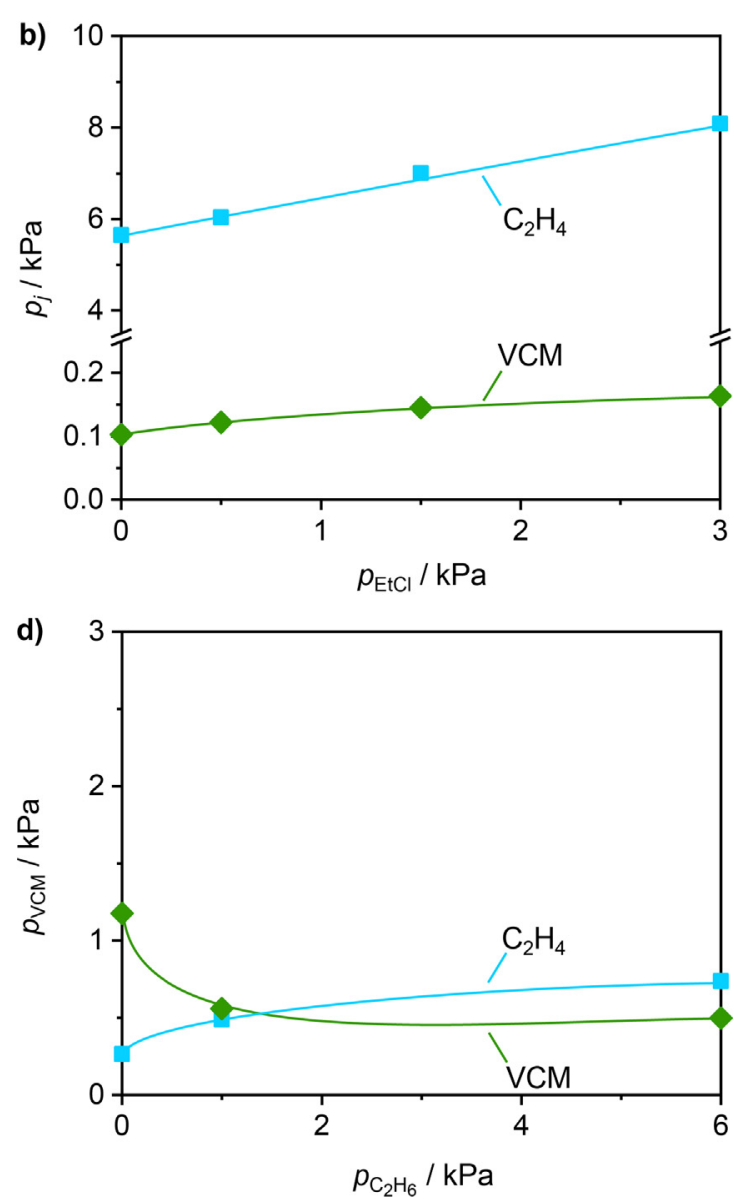

Fig. 4. (a) Scheme depicting the co-feeding strategy in ethene oxychlorination and EDC dehydrochlorination to study the influence of ethyl chloride or ethane on the VCM formation in these reactions. Partial ethene and VCM pressures as a function of the partial pressure of (b) ethyl chloride or (c) ethane in ethene oxychlorination, and of (d) ethane in EDC dehydrochlorination in the presence of $\mathrm{HCl}$ and $\mathrm{O}_{2}$. Conditions are detailed in Table 1.
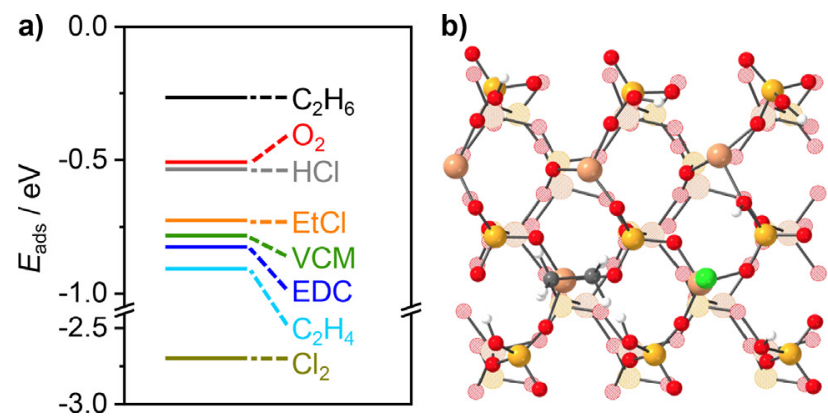

c)<smiles></smiles><smiles>O=P(O)(O)c1cccc(F)c1</smiles><smiles>P=C1C=CC=C1</smiles>

Fig. 5. (a) Adsorption energies of reactants and products on iron phosphate. (b) Illustration of ethane and $\mathrm{HCl}_{\text {adsorption on the } \mathrm{FePO}}$ surface. Color code: $\mathrm{Fe}$ : light brown, $\mathrm{P}$ : yellow, O: red, C: gray, $\mathrm{H}$ : white, $\mathrm{Cl}$ : green. (c) Schematic representation of the three different states of the iron active site investigated in this study: an uncapped oxygen near the iron center (left, gray), a fully coordinated oxygen near the iron center (middle, red), and a chlorine adsorbed on the iron center (right, green). The former highly reactive uncapped oxygen species was found irrelevant to the reaction due to their rarity in this material, linked to fast rehydration kinetics.

the $\mathrm{FePO}_{4}\left(\begin{array}{lll}1 & 0 & 2\end{array}\right)$ surface (Fig. 5a). While ethane, oxygen, and $\mathrm{HCl}$ adsorb relatively weakly, chlorine adsorbs strongly, indicating that chlorine will only leave the surface in form of a chlorinated hydrocarbon or $\mathrm{HCl}$. The investigated chlorinated hydrocarbons, i.e. $\mathrm{EtCl}$, EDC, and VCM, exhibit similar medium adsorption energies, while ethene is the most strongly adsorbed hydrocarbon. Fig. 5b exemplifies the simultaneous adsorption of ethane and $\mathrm{HCl}$ on the $(3 \times 1) \mathrm{FePO}_{4}\left(\begin{array}{ll}1 & 0\end{array}\right)$ supercell, which even though adaptive e.g. upon adsorption of chlorine [53], allows consideration of multiple adsorbates for evaluation of reaction profiles. The complete reaction network of ethane and ethene oxychlorination was investigated considering three environments for the active sites of $\mathrm{FePO}_{4}$ : an iron center with an uncapped oxygen nearby, an iron center with a neighboring fully coordinated oxygen, or a chlorinated iron center (Figs. $5 c$ and 6). However, even though the creation of uncapped oxygen sites is feasible at low or no chlorine coverage due to dissociative adsorption of molecular oxygen, which occupies two Fe sites and from where one adsorbed oxygen atom can catch a hydrogen from a capped oxygen $(\Delta E=0.84 \mathrm{eV})$, higher degrees of surface chlorination prohibit the formation of this state due to blockage of necessary empty neighboring Fe centers [53]. Previous studies on the halogen surface coverage during 
ethane oxychlorination revealed that under typical reaction conditions, 55\% of the Fe centers are chlorinated [53], which indicates that the main sites available for reaction are a free iron center with a fully coordinated oxygen and a chlorinated Fe center.

Ethane activation proceeds through hydrogen abstraction on a fully coordinated $\mathrm{O}$ and a free Fe center $\left(E_{\mathrm{a}}=0.66 \mathrm{eV}\right)$, resulting in an $\mathrm{OH}$ group and the surface bound $\mathrm{C}_{2} \mathrm{H}_{5}$ intermediate. Further addition of $\mathrm{Cl}$ from a neighboring chlorinated $\mathrm{Fe}$ center to form ethyl chloride is barrierless and exothermic by $1.73 \mathrm{eV}$ (Figs. 6 and 7). Direct formation of ethene in the absence of $\mathrm{Cl}$ by sequential abstraction of two $\mathrm{H}$ from ethane is theoretically possible when only considering the energy barrier for $\mathrm{H}$ abstraction from the surface-bound $\mathrm{C}_{2} \mathrm{H}_{5}$ intermediate $\left(E_{\mathrm{a}}=0.82 \mathrm{eV}\right.$, Table 2$)$. However, as demonstrated in oxidative dehydrogenation, which was not found possible under the experimental conditions in steady-state tests in this study, the free rotor nature of the $\mathrm{CH}_{3}$ group prevents this reactive event. Ethyl chloride dehydrochlorination could proceed in two ways, either through individual steps or one concerted step. Individual abstraction of hydrogen would however only work on an uncapped oxygen, while the fully coordinated oxygen as $\mathrm{H}$ recipient renders an activation energy of $2.10 \mathrm{eV}$. If instead, the chlorine attached to an Fe center acts as a hydrogen stripping agent, the reaction exhibits a lower barrier $\left(E_{\mathrm{a}}=1.75 \mathrm{eV}\right)$, ending up in $\mathrm{HCl}$, while creating the surface bound $\mathrm{C}_{2} \mathrm{H}_{4} \mathrm{Cl}$ intermediate. Elimination of chlorine from there to form ethene is exothermic by $0.61 \mathrm{eV}$ and comparatively easy $\left(E_{\mathrm{a}}=0.67 \mathrm{eV}\right)$. However, forming ethene from ethyl chloride is much easier though a concerted $\mathrm{H}-\mathrm{Cl}$ abstraction, again on a chlorinated Fe center and a free Fe center, through a barrier of $1.46 \mathrm{eV}$ (Fig. 7). In addition, formation of ethene and $\mathrm{HCl}$ at the same time and their release to the gasphase, is strongly favored entropically. Continued reaction of ethene requires the backreaction, i.e. chlorine addition, forming again the $\mathrm{C}_{2} \mathrm{H}_{4} \mathrm{Cl}$ intermediate $\left(E_{\mathrm{a}}=1.28 \mathrm{eV}\right)$. Even though a second addition of $\mathrm{Cl}$ to this intermediate exhibits a slightly lower barrier than $\mathrm{H}$ stripping to directly form $\mathrm{VCM}\left(E_{\mathrm{a}}=0.40 \mathrm{eV}\right.$ versus $\left.E_{\mathrm{a}}=0.92 \mathrm{eV}\right)$, the second process is thermodynamically favored $(\Delta E=-1.39 \mathrm{eV}$ versus $\Delta E=-1.80 \mathrm{eV})$. In addition, zero-point vibrational energy contributions decrease the barrier for $\mathrm{H}$ abstraction by about $0.2 \mathrm{eV}$ in comparison to $\mathrm{Cl}$ addition and the probability for a second chlorinated Fe site in range is low, leading to direct VCM formation as most likely option. However, if EDC is formed, transformation to VCM proceeds through a concerted $\mathrm{H}-\mathrm{Cl}$ stripping step on a chlorinated Fe center $\left(E_{\mathrm{a}}=1.23 \mathrm{eV}\right)$, analogue to $\mathrm{EtCl}$ dehydrochlorination, while individual steps through the surface

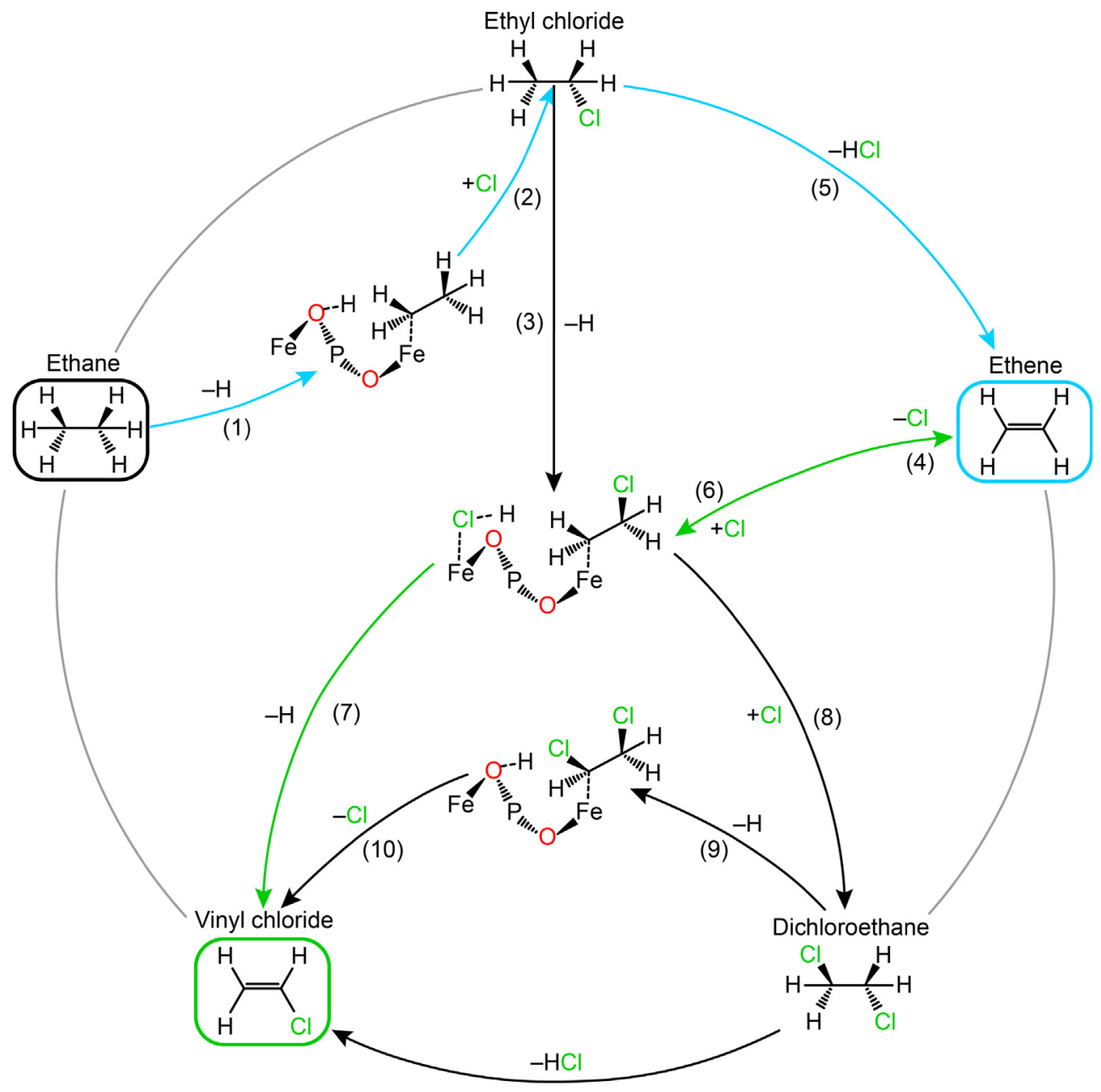

(11)

Fig. 6. Reaction network of ethane and ethene oxychlorination on $\mathrm{FePO}_{4}$, where reactants, highlighted by the black and blue boxes, and products are depicted on the outside and surface-bound intermediates within the circle, which are depicted with a surface excerpt of two Fe, two O, and one P atom. Blue arrows indicate the preferred pathway for ethane oxychlorination to ethene and green arrows the favored route for (further) transformation to vinyl chloride. The numbers (1)-(11) close to the arrows correspond to Table 2, indicating energy barriers, reaction enthalpies, and frequencies. 

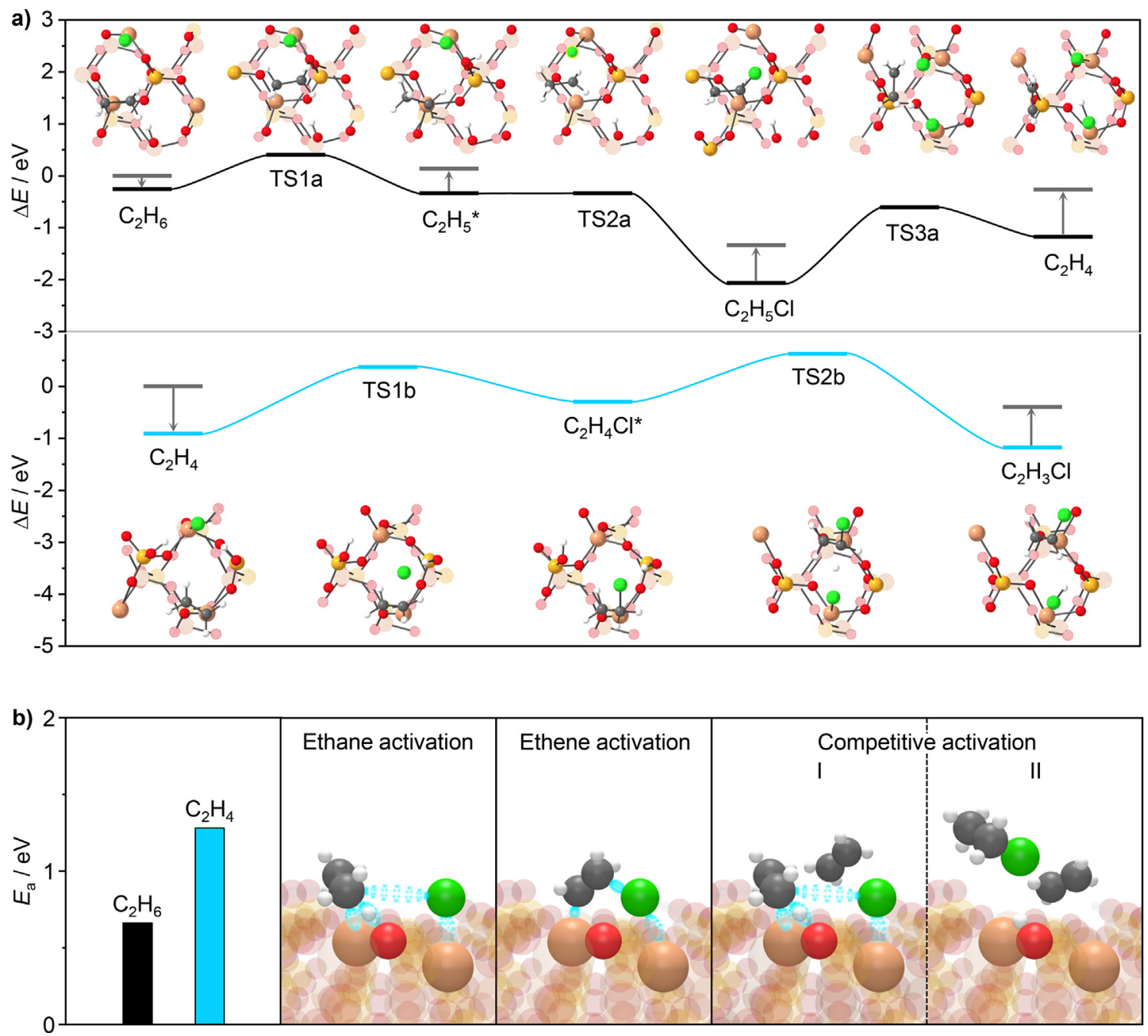

Fig. 7. (a) Reaction profiles of the preferred pathways of ethane (black, top) and ethene (blue, bottom) oxychlorination on FePO ${ }_{4}$, where gray lines indicate the energy gained or necessary to adsorb or desorb from and to the gas phase. The labels indicate reactants, products, transition states, and surface-bound intermediates indicated with an asterisk. The top and bottom illustrations depict the corresponding relevant excerpts of the surface. (b) Scheme depicting the energy barriers for ethane and ethene activation (panel 1) and illustrations of ethane (panel 2), ethene (panel 3), and competitive activation (panels 4, 5). Ethane prevails in the latter by forming ethyl chloride (panel 5), in turn cleaning the surface of chlorine and depleting the necessary active site combination for ethene activation. Color code: Fe: light brown, P: yellow, O: red, C: gray, H: white, $\mathrm{Cl}$ : green. The blue highlighting indicates the bond changes in the transition state.

bound intermediate $\mathrm{C}_{2} \mathrm{H}_{4} \mathrm{Cl}_{2}$ are excluded $\left(E_{\mathrm{a}}=2.07 \mathrm{eV}\right)$. Nevertheless, oxychlorination requires the formation of surface bound intermediates entailing restriction of molecule movement. On the other hand, dehydrochlorination in a concerted step proceeds without formation of surface intermediates, explaining why the latter reactions can still proceed at lower temperature. In conclusion, as illustrated in Fig. 7a, ethane oxychlorination most likely proceeds through two individual steps to form ethyl chloride, which is subsequently dehydrochlorinated in a concerted step to form ethene. Ethene oxychlorination in turn starts by chlorine addition and subsequent dehydrogenation directly to vinyl chloride. One reason why ethene does not react further to VCM in ethane oxychlorination, might be that the barrier for ethene desorption lies within a similar range as that of the addition of chlorine. However, this also holds for the $\mathrm{HCl}$ abstraction from ethyl chloride, which would entail no formation of ethene, which is why that explanation attempt must be discarded.

Instead, the cause for the inhibition of ethene to VCM transformation in the presence of ethane is linked to the competition of the alkane and the alkene for the same active site combination
(Fig. 7b). Both hydrocarbons necessitate one free Fe center and one chlorinated counterpart, while ethane needs an additional fully coordinated oxygen neighboring, which is very likely considering the stoichiometry of the surface. Panel two and three of Fig. 7b illustrate the activation of ethane, including hydrogen stripping and barrierless addition of chlorine to form ethyl chloride, and activation of ethene by addition of chlorine to form the $\mathrm{C}_{2} \mathrm{H}_{4} \mathrm{Cl}$ intermediate. As depicted in the first panel, ethane activation is largely favored, which leads to the two right panels, in which ethane is activated by depletion of the active site, so that the active site for ethene activation is not anymore available. This entails that as long as ethane is present in the reaction mixture, it cleans the surface of necessary active site combinations for ethene activation. Thus ethene transformation to VCM is suppressed, leading to the observed diverging selectivity patterns. This phenomenon is also responsible for the analogue suppression effect observed in EDC dehydrochlorination, where the same active site combination is responsible for concerted $\mathrm{H}-\mathrm{Cl}$ abstraction to form VCM, thus representing the descriptor for the ethane and ethene competition on iron phosphate. 
Table 2

Elementary steps, state of the iron active site, reaction $(\Delta E)$ and activation energies $\left(E_{\mathrm{a}}\right)$, as well as imaginary frequencies of the transition states $\left(v_{\mathrm{i}}\right)$ investigated in ethane and ethene oxychlorination on $\mathrm{FePO}_{4}$.

\begin{tabular}{|c|c|c|c|c|c|}
\hline Elementary step & State of the iron active site ${ }^{a}$ & $\Delta E / \mathrm{eV}$ & $E_{\mathrm{a}} / \mathrm{eV}$ & $v_{\mathrm{i}} / \mathrm{cm}^{-1}$ & $\#^{\mathrm{b}}$ \\
\hline $\mathrm{HCl}+{ }^{*}+\mathrm{O}-\mathrm{fc}^{*} \rightarrow \mathrm{H}_{\mathrm{O}-\mathrm{fc}}{ }^{*}+\mathrm{Cl}^{*}$ & $\mathrm{O}-\mathrm{fc}$ & -0.53 & - & - & \\
\hline $\begin{array}{l}\text { Ethane oxychlorination } \\
\mathrm{C}_{2} \mathrm{H}_{6}{ }^{*}+\mathrm{O}-\mathrm{u}^{*} \rightarrow \mathrm{C}_{2} \mathrm{H}_{5}{ }^{*}+\mathrm{H}_{\mathrm{O}-\mathrm{u}}{ }^{*} \\
\mathrm{C}_{2} \mathrm{H}_{6}{ }^{*}+\mathrm{O}-\mathrm{fc}^{*} \rightarrow \mathrm{C}_{2} \mathrm{H}_{5}{ }^{*}+\mathrm{H}_{\mathrm{O}-\mathrm{fc}}{ }^{*} \\
\mathrm{C}_{2} \mathrm{H}_{6}{ }^{*}+\mathrm{Cl}^{*} \rightarrow \mathrm{C}_{2} \mathrm{H}_{5}{ }^{*}+\mathrm{HCl}^{*} \\
\mathrm{C}_{2} \mathrm{H}_{5}{ }^{*}+\mathrm{Cl}^{*} \rightarrow \mathrm{C}_{2} \mathrm{H}_{5} \mathrm{Cl}^{*}+{ }^{*} \\
\mathrm{C}_{2} \mathrm{H}_{5} \mathrm{Cl}^{*}+\mathrm{O}-\mathrm{u}^{*} \rightarrow \mathrm{C}_{2} \mathrm{H}_{4} \mathrm{Cl}^{*}+\mathrm{H}_{\mathrm{O}-\mathrm{u}}{ }^{*} \\
\mathrm{C}_{2} \mathrm{H}_{5} \mathrm{Cl}^{*}+\mathrm{O}-\mathrm{fc}^{*} \rightarrow \mathrm{C}_{2} \mathrm{H}_{4} \mathrm{Cl}^{*}+\mathrm{H}_{\mathrm{O}-\mathrm{fc}}{ }^{*} \\
\mathrm{C}_{2} \mathrm{H}_{5} \mathrm{Cl}^{*}+\mathrm{Cl}^{*} \rightarrow \mathrm{C}_{2} \mathrm{H}_{4} \mathrm{Cl}^{*}+\mathrm{HCl}^{*} \\
\mathrm{C}_{2} \mathrm{H}_{4} \mathrm{Cl}^{*}+{ }^{*} \rightarrow \mathrm{C}_{2} \mathrm{H}_{4}{ }^{*}+\mathrm{Cl}^{*} \\
\mathrm{C}_{2} \mathrm{H}_{5} \mathrm{Cl}^{*}+\mathrm{O}-\mathrm{fc}^{*}+{ }^{*} \rightarrow \mathrm{C}_{2} \mathrm{H}_{4}{ }^{*}+\mathrm{H}_{\mathrm{O}-\mathrm{fc}}{ }^{*}+\mathrm{Cl}^{*} \\
\mathrm{C}_{2} \mathrm{H}_{5} \mathrm{Cl}^{*}+\mathrm{Cl}^{*}+{ }^{*} \rightarrow \mathrm{C}_{2} \mathrm{H}_{4}{ }^{*}+\mathrm{HCl}^{*}+\mathrm{Cl}^{*} \\
\mathrm{C}_{2} \mathrm{H}_{5}{ }^{*}+\mathrm{O}_{-} \mathrm{fc}^{*} \rightarrow \mathrm{C}_{2} \mathrm{H}_{4}{ }^{*}+\mathrm{H}_{\mathrm{O}-\mathrm{fc}}{ }^{*} \\
\mathrm{C}_{2} \mathrm{H}_{5}{ }^{*}+\mathrm{Cl}^{*} \rightarrow \mathrm{C}_{2} \mathrm{H}_{4}{ }^{*}+\mathrm{HCl}^{*}\end{array}$ & $\begin{array}{l}\mathrm{O}-\mathrm{u} \\
\mathrm{O}-\mathrm{fc} \\
\mathrm{Cl}^{*} \\
\mathrm{Cl}^{*} \\
\mathrm{O}-\mathrm{u} \\
\mathrm{O}-\mathrm{fc} \\
\mathrm{Cl}^{*} \\
\mathrm{Cl}^{*} \\
\mathrm{O}-\mathrm{fc} \\
\mathrm{Cl}^{*} \\
\mathrm{O}-\mathrm{fc} \\
\mathrm{Cl}^{*}\end{array}$ & $\begin{array}{l}0.05 \\
-0.08 \\
1.27 \\
-1.73 \\
-0.38 \\
1.33 \\
1.14 \\
-0.61 \\
0.42 \\
0.89 \\
-0.81 \\
-0.04\end{array}$ & $\begin{array}{l}1.23 \\
0.66 \\
2.04 \\
- \\
1.04 \\
2.10 \\
1.75 \\
0.67 \\
2.98 \\
1.46 \\
0.82 \\
0.91\end{array}$ & $\begin{array}{l}1247 \\
1419 \\
676 \\
159 \\
1563 \\
916 \\
514 \\
211 \\
1287 \\
230 \\
1291 \\
170\end{array}$ & $\begin{array}{l}(1) \\
(1) \\
(1) \\
(2) \\
(3) \\
(3) \\
(3) \\
(4) \\
(5) \\
(5)\end{array}$ \\
\hline $\begin{array}{l}\text { Ethene oxychlorination } \\
\mathrm{C}_{2} \mathrm{H}_{4}{ }^{*}+\mathrm{Cl}^{*} \rightarrow \mathrm{C}_{2} \mathrm{H}_{4} \mathrm{Cl}^{*}+{ }^{*} \\
\mathrm{C}_{2} \mathrm{H}_{4} \mathrm{Cl}^{*}+\mathrm{O}-\mathrm{fc}^{*} \rightarrow \mathrm{C}_{2} \mathrm{H}_{3} \mathrm{Cl}^{*}+\mathrm{H}_{\mathrm{O}-\mathrm{fc}^{*}}{ }^{*} \\
\mathrm{C}_{2} \mathrm{H}_{4} \mathrm{Cl}^{*}+\mathrm{Cl}^{*} \rightarrow \mathrm{C}_{2} \mathrm{H}_{3} \mathrm{Cl}^{*}+\mathrm{HCl}^{*} \\
\mathrm{C}_{2} \mathrm{H}_{4} \mathrm{Cl}^{*}+\mathrm{Cl}^{*} \rightarrow \mathrm{C}_{2} \mathrm{H}_{4} \mathrm{Cl}_{2}{ }^{*} \\
\mathrm{C}_{2} \mathrm{H}_{4} \mathrm{Cl}_{2}{ }^{*}+\mathrm{O}-\mathrm{fc}^{*} \rightarrow \mathrm{C}_{2} \mathrm{H}_{3} \mathrm{Cl}_{2}{ }^{*}+\mathrm{H}_{\mathrm{O}-\mathrm{fc}} \\
\mathrm{C}_{2} \mathrm{H}_{4} \mathrm{Cl}_{2}{ }^{*}+\mathrm{Cl}^{*} \rightarrow \mathrm{C}_{2} \mathrm{H}_{3} \mathrm{Cl}_{2}{ }^{*}+\mathrm{HCl}^{*} \\
\mathrm{C}_{2} \mathrm{H}_{3} \mathrm{Cl}_{2}{ }^{*}+{ }^{*} \rightarrow \mathrm{C}_{2} \mathrm{H}_{3} \mathrm{Cl}^{*}+\mathrm{Cl}^{*} \\
\mathrm{C}_{2} \mathrm{H}_{4} \mathrm{Cl}_{2}{ }^{*} \mathrm{Cl}^{*}+{ }^{*} \rightarrow \mathrm{C}_{2} \mathrm{H}_{3} \mathrm{Cl}^{*}+\mathrm{HCl}^{*}+\mathrm{Cl}^{*}\end{array}$ & $\begin{array}{l}\mathrm{Cl}^{*} \\
\mathrm{O}-\mathrm{fc} \\
\mathrm{Cl}^{*} \\
\mathrm{Cl}^{*} \\
\mathrm{O}-\mathrm{fc} \\
\mathrm{Cl}^{*} \\
\mathrm{Cl}^{*} \\
\mathrm{Cl}^{*}\end{array}$ & $\begin{array}{l}0.61 \\
-0.87 \\
-1.80 \\
-1.39 \\
1.62 \\
1.54 \\
-0.39 \\
0.11\end{array}$ & $\begin{array}{l}1.28 \\
1.40 \\
0.92 \\
0.40 \\
2.07 \\
2.79 \\
0.61 \\
1.23\end{array}$ & $\begin{array}{l}211 \\
1031 \\
902 \\
328 \\
906 \\
1413 \\
101 \\
180\end{array}$ & $\begin{array}{l}(6) \\
(7) \\
(7) \\
(8) \\
(9) \\
(9) \\
(10) \\
(11)\end{array}$ \\
\hline
\end{tabular}

a The active site of iron phosphate is characterized by an iron center and a neighboring oxygen atom. However, the oxygen atom can either be an uncapped oxygen ( $\mathrm{O}-\mathrm{u}$ ) or a fully coordinated oxygen $(\mathrm{O}-\mathrm{fc})$ and the iron center can be chlorinated $\left(\mathrm{Cl}^{*}\right)$, as illustrated in Fig. $5 \mathrm{c}$.

b The number of the elementary step (\#) corresponds to the label numbers in Fig. 6.

\subsection{Extension to other catalysts}

Even though the investigated catalysts in this study have very different structures and material properties, the performance in ethane and ethene oxychlorination exhibits, aside from obvious differences regarding combustion products, comparable patterns with respect to ethene or VCM formation (Fig. 8a). Especially $\mathrm{FePO}_{4}$ and $\mathrm{EuOCl}$ stand out as materials with strong diverging selectivities for ethene and VCM in ethane and ethene oxychlorination. LaOCl showed considerable selectivity towards ethene in ethane oxychlorination, with the major by-products being $\mathrm{CO}_{2}, \mathrm{CO}$ and traces of VCM. This contrast to the reported VCM selectivities in literature could be related to the much shorter residence time in our tests. In ethene oxychlorination, $\mathrm{LaOCl}$ mainly forms $\mathrm{CO}$ and various side-products, of which VCM is the most pronounced. The third group of materials is composed by $\mathrm{CeO}_{2}$ and $\mathrm{CuCl}_{2}$, which show the same or minimal selectivity to VCM in ethane and ethene oxychlorination. However, all of these materials show a drop of VCM formation in co-feeding studies (Fig. 8b), indicating that the phenomenon of VCM inhibition through ethane is material independent, yet expressed with a material dependent magnitude. In search of a simple common descriptor classifying the investigated, and possibly other, catalysts as materials which exhibit diverging selectivities in ethane and ethene oxychlorination, their corresponding reaction energies of ethane and ethene activation, is depicted in Fig. 8c. The copper-based catalyst was not modelled due to its structural complexity with $\mathrm{CuCl}_{2}$ and $\mathrm{KCl}-$ and $\mathrm{LaCl}_{3}-$ dopants on $\mathrm{Al}_{2} \mathrm{O}_{3}$ and phase transitions of the involved metal (oxy-)chlorides, which would go beyond the scope of this work. All other materials lie in the lower right corner in Fig. 8c, implying that the reaction energy for ethane activation is lower than for ethene activation, which, following the above reasoning, coincides with the observed inhibition of VCM formation through ethane. Regarding the strength of the VCM suppression effect of ethane, it is noteworthy to add that the influence of the hydrocarbon activation energies overlaps with the amount of chlorine, and thus the availability of necessary active sites on the surface. Therefore, materials such as $\mathrm{CuCl}_{2}$ and $\mathrm{CeO}_{2}$, which generally exhibit higher degrees of chlorination than $\mathrm{EuOCl}$ or $\mathrm{FePO}_{4}$, show a lower degree of VCM suppression by ethane in ethene oxychlorination.

\section{Conclusions}

This work revealed the mechanistic origin of the diverging selectivity patterns of ethane and ethene oxychlorination on iron phosphate and then extrapolated to a larger class of heterogeneous catalysts, by a combination of steady-state tests, temporal analysis of products, and computational analysis by density functional theory. Catalytic evaluation shows that ethane oxychlorination selectively yields ethene while VCM formation is inhibited, which can be formed by ethene oxychlorination to VCM in a separated step under the same conditions. An overall sequential mechanism from ethane to VCM could be excluded by temporal analysis of products, while ethane oxychlorination to ethene proceeds through ethyl chloride and VCM can be directly formed from ethene. This phenomenon of VCM suppression in ethane oxychlorination was corroborated by co-feeding ethane in ethene oxychlorination, showing a decrease of VCM formation. Simulations reveal that this effect is not linked to exclusions in the reaction network, which allows simultaneous or sequential ethane and ethene oxychlorination. Instead, competition between the alkane and the alkene for a combination of chlorinated and free iron sites hinders ethene activation, as ethane activation is largely favored. Therefore, and because of large entropy gains upon simultaneous desorption of ethene and $\mathrm{HCl}$ after concerted $\mathrm{EtCl}$ dehydrochlorination, ethene desorption is more likely than further reaction to VCM. Thus, ethane activation leads to local depletion of the necessary sites for ethene oxychlorination, leaving the competing ethene over an inert surface. The phenomenon of VCM suppression through ethane was observed as well over a range of other oxychlorination catalysts, yet with variable strength, most likely linked to the degree of chlorination of the surface. Ultimately, this study shed light on the underlying root cause of the experimentally observed 
a)
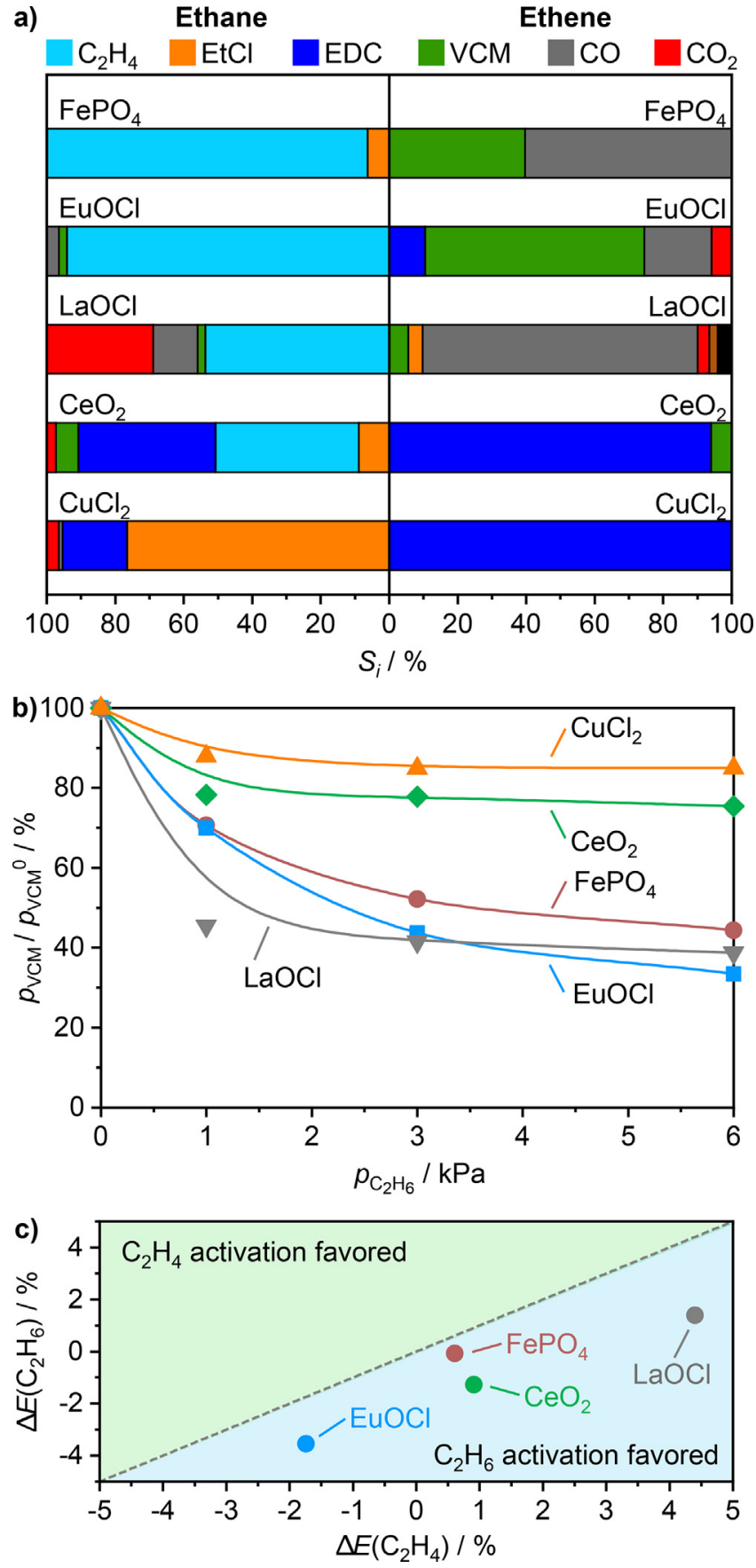

Fig. 8. (a) Product distribution at $20 \%$ hydrocarbon conversion in ethane and ethene oxychlorination over oxychlorination catalysts. (b) Ratio of partial VCM pressure and initial partial VCM pressure as a function of the co-feed partial ethane pressure in ethene oxychlorination over oxychlorination catalysts. (c) Reaction energy of ethane versus ethene activation over oxychlorination catalysts. Conditions are detailed in Table 1.

diverging selectivity patterns in ethane and ethene oxychlorination on an iron phosphate catalyst and extension to other catalyst families, providing a basis for further evaluation of the potential of an ethane feedstock for oxychlorination over copper-free catalysts in the context of PVC production.

\section{Acknowledgements} $16-1$.

\section{Appendix A. Supplementary material}

\section{References}

[1] Businesswire, Global Polyvinyl Chloride (PVC) Market Worth USD 72.330 Billion by 2021, 2016. http://www.businesswire.com/news/home/ 20161115006496/en/Global-Polyvinyl-Chloride-PVC-Market-Worth-USD (accessed September 24, 2017).

[2] K. Weissermel, H.-J. Arpe, Vinyl-Halogen and vinyl-oxygen compounds, in: Industrial Organic Chemistry, fourth ed., Wiley-VCH, Weinheim, 2008, pp. 217-238.

[3] E.-L. Dreher, K.K. Beutel, J.D. Myers, T. Lübbe, S. Krieger, L.H. Pottenger, Chloroethanes and Chloroethylenes, in: Ullmann's Encyclopedia of Industrial Chemistry, Wiley-VCH, Weinheim, 2014, p. 2.

[4] K. Mulder, M. Knot, PVC plastic: a history of systems development and entrenchment, Technol. Soc. 23 (2001) 265-286, https://doi.org/10.1016/ S0160-791X(01)00013-6.

[5] N.B. Muddada, U. Olsbye G. Leofanti, D. Gianolio, F. Bonino, S. Bordiga, T. Fuglerud, S. Vidotto, A. Marsella, C. Lamberti, Quantification of copper phases, their reducibility and dispersion in doped- $\mathrm{CuCl}_{2} / \mathrm{Al}_{2} \mathrm{O}_{3}$ catalysts for ethylene oxychlorination, Dalton Trans. 39 (2010) 8437-8449, https://doi.org/10.1039/ c0dt00488j.

[6] N.B. Muddada, U. Olsbye, T. Fuglerud, S. Vidotto, A. Marsella, S. Bordiga, D. Gianolio, G. Leofanti, C. Lamberti, The role of chlorine and additives on the density and strength of Lewis and Brønsted acidic sites of $\gamma-\mathrm{Al}_{2} \mathrm{O}_{3}$ support used in oxychlorination catalysis: a FTIR study, J. Catal. 284 (2011) 236-246, https:// doi.org/10.1016/j.jcat.2011.08.014.

[7] J. Liu, X. Lü, G. Zhou, K. Zhen, W. Zhang, T. Cheng, Effect of $\mathrm{KCl}$ on $\mathrm{CuCl}_{2} / \gamma-\mathrm{Al}_{2} \mathrm{O}_{3}$ catalyst for oxychlorination of ethane, React. Kinet. Catal. Lett. 88 (2006) 315323, https://doi.org/10.1007/s11144-006-0067-6.

[8] L. Xueju, L. Jie, Z. Guangdong, Z. Kaiji, L. Wenxing, C. Tiexin, Ethane oxychlorination over $\gamma-\mathrm{Al}_{2} \mathrm{O}_{3}$ supported $\mathrm{CuCl}_{2}-\mathrm{KCl}-\mathrm{LaCl}$, Catal. Lett. 100 (2005) 153-159, https://doi.org/10.1007/s10562-004-3448-3.

[9] Z. Li, G. Zhou, C. Li, T. Cheng, Effect of Pr on copper-based catalysts for ethane oxychlorination, Catal. Commun. 40 (2013) 42-46, https://doi.org/10.1016/ j.catcom.2013.05.020.

[10] J.S. Naworski, E.S, Velez, Oxychlorination of ethylene, in: Applied Industrial Catalysis, Academic Press, New York, 1983, pp. 239-273.

[11] M. Malentacchi, C. Rubini, Oxychlorination catalytic composition for controlling exothermic reactions in a fixed bed, EP 1020222 B1, 2004.

[12] N.B. Muddada, T. Fuglerud, C. Lamberti, U. Olsbye, Tuning the activity and selectivity of $\mathrm{CuCl}_{2} / \gamma-\mathrm{Al}_{2} \mathrm{O}_{3}$ ethene oxychlorination catalyst by selective promotion, Top. Catal. 57 (2014) 741-756, https://doi.org/10.1007/s11244013-0231-y.

[13] N.B. Muddada, U. Olsbye, L. Caccialupi, F. Cavani, G. Leofanti, D. Gianolio, S. Bordiga, C. Lamberti, Influence of additives in defining the active phase of the ethylene oxychlorination catalyst, Phys. Chem. Chem. Phys. 12 (2010) 56055618, https://doi.org/10.1039/b926502n.

[14] J.P. Henley, M.E. Jones, D.A. Hickman, K.A. Marshall, D.J. Reed, W.D. Clarke, M. M. Olken, L.E. Walko, Process for vinyl chloride manufacture from ethane and ethylene with partial $\mathrm{HCl}$ recovery from reactor effluent, US 6933417 B1, 2005.

[15] W.D. Mross, Alkali doping in heterogeneous catalysis, Catal. Rev. -Sci. Eng. 25 (1983) 591-637, https://doi.org/10.1080/01614948308078057.

[16] M. Graulier, Process for the oxychlorination of ethylenic hydrocarbons, GB1326428, 1973.

[17] J.D. Scott, Oxychlorination catalyst composition and an oxychlorination process using it, US 5011808, 1991.

[18] F.E. Van Rooijen, A. De Bruijn, J.J. Nieuwland, Catalytic oxychlorination, US 0054708 A1, 2009.

[19] M. Scharfe, P.A. Lira-Parada, V. Paunovic, M. Moser, A.P. Amrute, J. PérezRamírez, Oxychlorination-dehydrochlorination chemistry on bifunctional ceria catalysts for intensified vinyl chloride production, Angew. Chem. Int. Ed. 55 (2016) 3068-3072, https://doi.org/10.1002/anie.201510903.

[20] M. Scharfe, P.A. Lira-Parada, A.P. Amrute, S. Mitchell, J. Pérez-Ramírez, Lanthanide compounds as catalysts for the one-step synthesis of vinyl chloride from ethylene, J. Catal. 344 (2016) 524-534, https://doi.org/ 10.1016/j.jcat.2016.10.026.

[21] A. Shalygin, E. Paukshtis, E. Kovalyov, B. Balzhinimaev, Light olefins synthesis from $C_{1}-C_{2}$ paraffins via oxychlorination processes, Front. Chem. Sci. Eng. 7 (2013) 279-288, https://doi.org/10.1007/s11705-013-1338-1.

[22] R.T. Carrol, E.J. De Witt, L.E. Trapasso, Oxychlorination of lower alkanes, US3173962, 1965

[23] Q. Zhou, R. Hu, Y. Jia, H. Wang, The role of $\mathrm{KCl}$ in $\mathrm{FeCl}_{3}-\mathrm{KCl} / \mathrm{Al}_{2} \mathrm{O}_{3}$ catalysts with enhanced catalytic performance for ethane oxychlorination, Dalton Trans. 46 (2017) 10433-10439, https://doi.org/10.1039/C7DT01957B.

[24] R. Lin, A.P. Amrute, J. Pérez-Ramírez, Halogen-mediated conversion of hydrocarbons to commodities, Chem. Rev. 117 (2017) 4182-4247, https:// doi.org/10.1021/acs.chemrev.6b00551.

[25] L. Yang, R. Hu, H. Li, Y. Jia, Q. Zhou, H. Wang, The effect of interaction between $\mathrm{La}_{2} \mathrm{AlCOO}_{6}$ and $\mathrm{CuCl}_{2}$ on ethane oxychlorination, J. Ind. Eng. Chem. 56 (2017) 120-128, https://doi.org/10.1016/j.jiec.2017.07.004. 
[26] C. Li, G. Zhou, L. Wang, S. Dong, J. Li, T. Cheng, Effect of ceria on the MgO- $\gamma-$ $\mathrm{Al}_{2} \mathrm{O}_{3}$ supported $\mathrm{CeO}_{2} / \mathrm{CuCl}_{2} / \mathrm{KCl}$ catalysts for ethane oxychlorination, Appl. Catal., A 400 (2011) 104-110, https://doi.org/10.1016/j.apcata.2011.04.017.

[27] D. Shi, R. Hu, Q. Zhou, L. Yang, Catalytic activities of supported perovskite promoter catalysts $\mathrm{La}_{2} \mathrm{NiMnO}_{6}-\mathrm{CuCl}_{2} / \gamma-\mathrm{Al}_{2} \mathrm{O}_{3}$ and $\mathrm{La}_{1.7} \mathrm{~K}_{0.3} \mathrm{NiMnO}_{6}-\mathrm{CuCl}_{2} / \gamma$ $\mathrm{Al}_{2} \mathrm{O}_{3}$ for ethane oxychlorination, Chem. Eng. J. 288 (2016) 588-595, https:// doi.org/10.1016/j.cej.2015.12.035.

[28] I.M. Clegg, R. Hardman, Vinyl chloride production process, US5728905, 1998.

[29] T. Haymon, J. Henley, D. Hickman, M. Jones, M. Miller, T. Morris, D. Reed, L Samson, S. Smith, W. Clarke, Process for vinyl chloride manufacture from ethane and ethylene with air feed and alternative $\mathrm{HCl}$ processing methods, WO02094752, 2004.

[30] D.A. Hickman, M.E. Jones, Z.R. Jovanovic, M.M. Olken, S.G. Podkolzin, E.E Stangland, R.K. Thompson, Reactor scale-up for fluidized bed conversion of ethane to vinyl chloride, Ind. Eng. Chem. Res. 49 (2010) 10674-10681, https:// doi.org/10.1021/ie100423z.

[31] D. Shi, R. Hu, Q. Zhou, C. Li, Effect of Cr-doping on $\mathrm{CuCl}_{2}-\mathrm{KCl}-\mathrm{CeO}_{2} / \gamma-\mathrm{Al}_{2} \mathrm{O}_{3}$ catalysts for ethane oxychlorination, Appl. Catal., A 506 (2015) 91-99, https:// doi.org/10.1016/j.apcata.2015.08.037.

[32] G. Zichittella, N. Aellen, V. Paunović, A.P. Amrute, J. Pérez-Ramírez, Olefins from natural gas by oxychlorination, Angew. Chem. Int. Ed. 56 (2017) 1367013674, https://doi.org/10.1002/anie.201706624.

[33] G. Zichittella, B. Puértolas, S. Siol, V. Paunović, S. Mitchell, J. Pérez-Ramírez, An activated TiC-SiC composite for natural gas upgrading via catalytic oxyhalogenation, ChemCatChem. 10 (2018) 1282-1290, https://doi.org/ 10.1002 /cctc. 201701632

[34] M. Scharfe, M. Capdevila-Cortada, V.A. Kondratenko, E.V. Kondratenko, S. Colussi, A. Trovarelli, N. López, J. Pérez-Ramírez, Mechanism of ethylene oxychlorination on ceria, ACS Catal. 8 (2018) 2651-2663, https://doi.org/ 10.1021/acscatal.7b04431.

[35] J.S. Eden, Copper catalyst compositions for fluid-bed oxyhydrochlorination of ethylene, US4446249, 1984.

[36] J. Pérez-Ramírez, E.V. Kondratenko, Evolution, achievements, and perspectives of the TAP technique, Catal. Today 121 (2007) 160-169, https://doi.org/ 10.1016/j.cattod.2007.01.001.

[37] K. Morgan, N. Maguire, R. Fushimi, J.T. Gleaves, A. Goguet, M.P. Harold, E.V. Kondratenko, U. Menon, Y. Schuurman, G.S. Yablonsky, Forty years of temporal analysis of products, Catal. Sci. Technol. 7 (2017) 2416-2439, https://doi.org/ 10.1039/C7CY00678K.

[38] G. Kresse, J. Hafner, Ab initio molecular dynamics for liquid metals, Phys. Rev. B 47 (1993) 558-561, https://doi.org/10.1103/PhysRevB.47.558.

[39] G. Kresse, J. Furthmüller, Efficient iterative schemes for ab initio total-energy calculations using a plane-wave basis set, Phys. Rev. B 54 (1996) 1116911186, https://doi.org/10.1103/PhysRevB.54.11169.
[40] G. Kresse, J. Furthmüller, Efficiency of ab-initio total energy calculations for metals and semiconductors using a plane-wave basis set, Comput. Mater. Sci. 6 (1996) 15-50, https://doi.org/10.1016/0927-0256(96)00008-0.

[41] J.P. Perdew, K. Burke, M. Ernzerhof, Generalized gradient approximation made simple, Phys. Rev. Lett. 77 (1996) 3865-3868, https://doi.org/10.1103/ PhysRevLett. 77.3865.

[42] J. Hubbard, Electron correlations in narrow energy bands, Proc. R. Soc. Lond. A. Math. Phys. Sci. 276 (1963) 238-257, https://doi.org/10.1098/rspa.1963.0204.

[43] G.K.P. Dathar, D. Sheppard, K.J. Stevenson, G. Henkelman, Calculations of Li-ion diffusion in olivine phosphates, Chem. Mater. 23 (2011) 4032-4037, https:// doi.org/10.1021/cm201604g.

[44] J. Jung, M. Cho, M. Zhou, Ab initio study of the fracture energy of $\mathrm{LiFePO}_{4} / \mathrm{FePO}_{4}$ interfaces, J. Power Sources 243 (2013) 706-714, https://doi.org/10.1016/j. jpowsour.2013.06.030.

[45] M. Dixit, H. Engel, R. Eitan, D. Aurbach, M.D. Levi, M. Kosa, D.T. Major, Classical and quantum modeling of $\mathrm{Li}$ and $\mathrm{Na}$ diffusion in $\mathrm{FePO}_{4}$, J. Phys. Chem. C 119 (2015) 15801-15809, https://doi.org/10.1021/acs.jpcc.5b00405.

[46] S. Grimme, J. Anthony, S. Ehrlich, H. Krieg, A consistent and accurate ab initio parametrization of density functional dispersion correction (DFT-D) for the 94 elements H-Pu, J. Chem. Phys. 132 (2010) 154104-154122, https://doi.org/ $10.1063 / 1.3382344$.

[47] P.E. Blöchl, Projector augmented-wave method, Phys. Rev. B. 50 (1994) $17953-$ 17979, https://doi.org/10.1103/PhysRevB.50.17953.

[48] Y. Song, S. Yang, P.Y. Zavalij, M.S. Whittingham, Temperature-dependent properties of $\mathrm{FePO}_{4}$ cathode materials, Mater. Res. Bull. 37 (2002) 1249-1257, https://doi.org/10.1016/S0025-5408(02)00771-7.

[49] G. Henkelman, B.P. Uberuaga, H. Jónsson, A climbing image nudged elastic band method for finding saddle points and minimum energy paths, J. Chem. Phys. 113 (2000) 9901-9904, https://doi.org/10.1063/1.1329672.

[50] G. Henkelman, H. Jónsson, Improved tangent estimate in the nudged elastic band method for finding minimum energy paths and saddle points, J. Chem. Phys. 113 (2000) 9978-9985, https://doi.org/10.1063/1.1323224.

[51] M. Álvarez-Moreno, C. de Graaf, N. López, F. Maseras, J.M. Poblet, C. Bo, Managing the computational chemistry big data problem: the ioChem-BD platform, J. Chem. Inf. Model. 55 (2015) 95-103, https://doi.org/ 10.1021/ci500593j.

[52] ioChem-BD database available at: https://doi.org/10.19061/iochem-bd-6-16.

[53] G. Zichittella, M. Scharfe, B. Puertolas, V. Paunović, P. Hemberger, A. Bodi, L. Szentmiklósi, N. Lopez, J. Pérez-Ramírez, Halogen-dependent surface confinement governs selective alkane functionalization to olefins, Angew. Chem. Int. Ed. 58 (2019) 5877-5881, https://doi.org/10.1002/anie.201811669.

[54] M.D. Higham, M. Scharfe, M. Capdevila-Cortada, J. Pérez-Ramírez, N. López, Mechanism of ethylene oxychlorination over ruthenium oxide, J. Catal. 353 (2017) 171-180, https://doi.org/10.1016/j.jcat.2017.07.013. 